AperTO - Archivio Istituzionale Open Access dell'Università di Torino

\title{
Simulation and Experiment Reveal a Complex Scenario for the Adsorption of an Antifungal Drug in Ordered Mesoporous Silica
}

\section{This is the author's manuscript}

Original Citation:

\section{Availability:}

This version is available http://hdl.handle.net/2318/1526609

since 2021-03-10T16:47:06Z

Published version:

DOI:10.1021/acs.jpcc.5b02666

Terms of use:

Open Access

Anyone can freely access the full text of works made available as "Open Access". Works made available under a Creative Commons license can be used according to the terms and conditions of said license. Use of all other works requires consent of the right holder (author or publisher) if not exempted from copyright protection by the applicable law. 
This document is confidential and is proprietary to the American Chemical Society and its authors. Do not copy or disclose without written permission. If you have received this item in error, notify the sender and delete all copies.

\section{Simulation and experiment reveal a complex scenario for the adsorption of an antifungal drug in ordered mesoporous silica}

\begin{tabular}{|r|l|}
\hline Journal: & The Journal of Physical Chemistry \\
\hline Manuscript ID: & Draft \\
\hline Manuscript Type: & Article \\
\hline Complete List of Authors: & $\begin{array}{l}\text { Gignone, Andrea; Politecnico di Torino, Material Science and Chemical } \\
\text { Engineering } \\
\text { Delle Piane, Massimo; Università di Torino, Chimica } \\
\text { Corno, Marta; Università di Torino, Chimica } \\
\text { Ugliengo, Piero; Università di Torino, Chimica } \\
\text { Onida, Barbara; Politecnico di Torino, Material Science and Chemical } \\
\text { Engineering }\end{array}$ \\
\hline
\end{tabular}

SCHOLARONE

Manuscripts 


\title{
Simulation and experiment reveal a complex scenario for the
}

\section{adsorption of an antifungal drug in ordered mesoporous silica}

\author{
Andrea Gignone ${ }^{ж}$, Massimo Delle Piane ${ }^{\S}$, Marta Corno $^{\S}$, Piero Ugliengo ${ }^{\S *}$, Barbara Onida ${ }^{\text {** }}$ \\ ${ }^{\text {T}}$ Department of Applied Science and Technology, Politecnico di Torino, Corso Duca degli Abruzzi 24, 10129 Torino, \\ Italy. ${ }^{\S}$ Department of Chemistry and NIS, University of Torino, via Pietro Giuria 7, 10125, Torino, Italy \\ *Corresponding authors: piero.ugliengo@unito.it, barbara.onida@polito.it \\ KEYWORDS: mesoporous silica, MSU-H, drug delivery, clotrimazole, DFT, adsorption
}

\begin{abstract}
Ordered mesoporous silicas have been widely investigated as drug carriers in several fields, from tissue engineering to cancer therapy. The knowledge of the specific interactions between the surface of mesoporous silicas and drugs is necessary to guide development of new and improved drug delivery systems. However, such knowledge is still scarce, due to the arduous interpretation of experimental results. In this work, we characterize the incorporation of clotrimazole, a common antifungal drug, inside ordered mesoporous silica by means of a joint computational and experimental approach. Experimentally the drug was loaded through supercritical $\mathrm{CO}_{2}$ and its adsorption investigated through infrared spectroscopy, $\mathrm{N}_{2}$ adsorption isotherms and thermogravimetric analysis. Modelling involved static and dynamic Density Functional Theory simulations of clotrimazole adsorbed on realistic models of amorphous silica surfaces. A good agreement between the computational and experimental results was obtained, concerning the energies of adsorption, the infrared spectra and the distribution of drug inside the mesopores. However, a complete interpretation of the experimental results was possible only when simultaneously considering all the complex aspects of the drug-silica interaction. Indeed, the combination of both approaches allowed us to describe the drug-silica interface as a mix of multiple interaction configurations, based on a subtle balance of hydrogen bonding and dispersion interactions. Furthermore, at high drug loading, clotrimazole molecules are statistically distributed on the pore walls forming an adsorbed molecular layer. Finally, notwithstanding the
\end{abstract}


stable interactions, the drug still exhibits a significant mobility at room temperature, moving on a complex potential energy surface, as revealed by molecular dynamics simulations.

\section{INTRODUCTION}

Over the past three decades, a rapid growth has affected the research area of drug delivery, aiming at optimizing drug efficiency while simultaneously reducing adverse collateral effects. ${ }^{1}$ Several studies have reported that pharmacokinetics, drug efficiency and suppression of undesired side effects in different pathological conditions can be improved by correct timing of drug administration and controlled kinetics of drug release. ${ }^{2}$

Recently, the interest has concerned the use of mesoporous materials as controlled drug delivery matrixes thanks to their uniform mesoporous structures, high surface areas, tunable pore sizes and welldefined surface properties. ${ }^{3-6}$

In this context, Ordered Mesoporous Silicas (OMSs) have been widely investigated as drug carriers in several fields, from tissue engineering to cancer therapy. ${ }^{7}$ Initially, the research on OMSs for drug delivery was focused on the achievement of controlled release formulations. The release kinetics of drugs by OMSs depends on several carrier properties, including pore size, pore connectivity and the chemical composition of the surface. ${ }^{8}$ A recent emerging feature of OMS carriers is the enhanced oral bioavailability of molecules poorly soluble in water. ${ }^{9}$ It has been shown that both small and large molecular drugs can be entrapped within the mesopores by an impregnation process and liberated via a diffusion controlled mechanism. ${ }^{10}$

In the first pioneering work by Vallet-Regi et al., ${ }^{4}$ drug incorporation in MCM-41 was carried out by adsorption from a solution using hexane as solvent. Since the long-term toxicity of n-hexane in humans is well known, ${ }^{11,12}$ many other solvents have been studied for the incorporation. The incorporation by supercritical carbon dioxide $\left(\mathrm{scCO}_{2}\right)$ is an alternative to adsorption or impregnation from a liquid solution. ${ }^{13-15}$ Carbon dioxide is one of the most commonly used fluids in supercritical fluid technology. Its main advantages are a critical temperature close to ambient temperature $(304.25 \mathrm{~K})$ 
and a not too high critical pressure $(7.39 \mathrm{MPa}) .{ }^{16}$ In addition, it is non-flammable, has low cost and low toxicity. Being a supercritical fluid, its physical properties are halfway between a gas and a liquid; in particular, it has a solvent power like a liquid and a high diffusivity like a gas. At pressures and temperatures not too far from its critical point, a supercritical fluid has a high compressibility, therefore its density and hence its solvent power are easily adjustable over a wide range with a minimal change in temperature or pressure.

When a drug is incorporated inside a material, such as mesoporous silica, the interactions occurring at its surface are of great importance. They can deeply influence stability, absorption and manufacturability of the formulation ${ }^{17}$ and, for drug delivery systems, are essential for determining the final performance of the product, i.e. maximum loading, release profile and shelf life. For these reasons, the development of improved pharmaceutical formulations requires a thorough knowledge of the physico-chemical features of these interactions. However, despite the scientific and technological relevance of this topic, the atomistic details of the implied interactions are rarely investigated. Experimentally, most studies deal with ibuprofen as a model drug incorporated in OMSs. ${ }^{18,19}$ Nevertheless, the observed ibuprofen behavior might not be applicable to other drugs and this may become a serious problem in the translation from basic research to clinical. Indeed, to our knowledge only few papers deal with the details of other drug-silica interactions. ${ }^{20,21}$ Molecular modeling can be an important tool in addressing the problem of studying drug-silica interactions. ${ }^{22}$ Some of us have already simulated, through ab-initio calculations, ibuprofen interacting with both silica surfaces and a realistic mesoporous silica model, providing a detailed description of the system and some clues to the interpretation of ambiguous experimental results. ${ }^{23-25}$

One of the characteristics of mesoporous silica materials is the presence of a high concentration of silanol groups $(\mathrm{SiOH})$ exposed on the pore walls. It has been shown that the adsorption of molecules on a silica surface (such as the pore walls) is mainly guided by the formation of H-bonds with silanols, but, especially with hydrophobic molecules, also London type interactions (dispersion) can play an important role. ${ }^{23}$ 
MSU-H is a two-dimensional, hexagonally OMS with large uniform mesopores synthesized through a nonionic supramolecular assembly pathway using sodium silicate as a silica source and the triblock copolymer Pluronic P123 $\left(\mathrm{EO}_{20} \mathrm{PO}_{70} \mathrm{EO}_{20}\right)$ as a structure-directing agent. The framework structure of MSU-H is analogous to that of SBA-15 and consists of large ordered pores connected by micropores in the pore walls. Morphology of MSU-H differs from that of SBA-15, in that SBA-15 mesostructures usually assemble into larger and more monolithic particles. ${ }^{26}$

Clotrimazole (CTZ) is an active principle ingredient poorly soluble in water and present in antifungal topical medications for the treatment of fungal infections (of both humans and animals). ${ }^{27}$ It is commonly available as an over-the-counter drug in various forms including creams, vaginal tablets and as troche or throat lozenge. Topically, CTZ is used for vulvovaginal candidiasis (yeast infection) or skin yeast infections. Troche or throat lozenge preparations are used for oropharyngeal candidiasis (oral thrush) or prophylaxis against oral thrush in neutropenic patients. CTZ is usually used 5 times daily for 14 days for oral thrush, twice daily for 2 to 8 weeks for skin infections, and once daily for 3 or 7 days for vaginal infections. For these reasons, finding controlled release system can give a good improvement to pharmaceutical formulations reducing the number of needed applications. ${ }^{28}$

The aim of this work is the investigation of clotrimazole (1-[(2-chlorophenyl)(diphenyl)methyl]-1Himidazole) incorporated inside MSU-H ordered mesoporous material, by means of a joint computational and experimental approach.

In the present work, $\mathrm{CTZ}$ is incorporated into $\mathrm{MSU}-\mathrm{H}$ with $\mathrm{scCO}_{2}$ following a previous work ${ }^{15}$ and characterized through Fourier Transform InfraRed Spectroscopy (FTIR), $\mathrm{N}_{2}$ adsorption isotherms and ThermoGravimetric analysis (TG). These results are compared and interfaced with static and dynamic quantum mechanical simulations, focused on the interactions between silanols groups and CTZ, evaluating also the contribution of dispersive forces being CTZ a highly hydrophobic molecule. Quantum mechanical modeling is used to help the interpretation of the experimental data, and to obtain a complete description of the MSU-H-CTZ system. Finally, our broader aim is to exploit the knowledge gained on this system for explaining the amorphization, stabilization and interaction 
phenomena of drugs on silica surfaces.

\section{COMPUTATIONAL AND EXPERIMENTAL DETAILS}

\section{Materials}

CTZ and Ordered Mesoporous Silica (MSU-H type) were purchased from Sigma-Aldritch. Carbon dioxide with a purity of $99.5 \%$ was supplied by SIAD.

\section{Drug loading}

The drug was loaded by the $\mathrm{scCO}_{2}$ incorporation process at $373 \mathrm{~K}, 50 \mathrm{MPa}$ for 12 hours. More details on the $\mathrm{scCO}_{2}$ process are reported in a previous work. ${ }^{15}$

\section{Computational details}

All the calculations were performed within the Density Functional Theory (DFT). Concerning static calculations, the developmental version of the CRYSTAL14 $\operatorname{code}^{29}$ in its massively parallel version ${ }^{30}$ was adopted and the computational approach is the same of Ref. ${ }^{23}$. Briefly, the chosen functional was the Perdew, Burke, and Enzerhof GGA (Generalized Gradient Approximation) exchangecorrelation functional (PBE), ${ }^{31}$ including the empirical Grimme's D2 correction, ${ }^{32}$ to describe the dispersive interactions (vdW). In the following, the superscript D means that Grimme's correction is included. Split valence double- (for Si atoms) and triple- $\zeta$ (for other atoms) Gaussian type basis sets plus polarization functions were used to describe the systems. ${ }^{33,34}$ Chlorine atoms were represented with a $86-311 \mathrm{G}^{*}$ basis set. ${ }^{35}$ Only the atomic coordinates of the two more superficial layers of each silica slab in the docking geometries were optimized, to compensate for the reduced thickness of the models. Starting geometries were generated so to maximize the interactions between the drug and the surface. Interaction energies, per unit cell per adsorbate molecule $(\Delta \mathrm{E})$, were calculated and corrected for the basis set superposition error (BSSE) according to the counter-poise methodology described in previous papers by Delle Piane et al. ${ }^{23,25}$ and reported in Supporting Information.

Harmonic frequencies were calculated with CRYSTAL14 at $\Gamma$ point and the infrared intensity for each normal mode was obtained by computing the dipole moment variation along the normal mode, 
adopting the Berry phase method. ${ }^{36}$ For the simulation of the IR spectra of the different structures, only a fragment consisting of the most interesting chemical groups has been considered for constructing the Hessian matrix and will be defined for each case in Results and Discussion.

Enthalpies $(\Delta \mathrm{H})$ of adsorption at standard temperature $(298 \mathrm{~K})$ were obtained from the vibrational partition functions, by applying the Zero Point Energies $(\Delta \mathrm{ZPE})$ and thermal $\left(\Delta \mathrm{E}_{\mathrm{T}}\right)$ corrections to the BSSE corrected electronic adsorption energies $\left(\Delta \mathrm{E}^{\mathrm{C}}\right)$ as $\Delta \mathrm{H}=\Delta \mathrm{E}^{\mathrm{C}}+\Delta \mathrm{ZPE}+\Delta \mathrm{E}_{\mathrm{T}}$.

Ab-initio molecular dynamics (AIMD) simulations were performed using the CP2K code. ${ }^{37}$ The Quickstep technique ${ }^{38}$ with a mixed plane wave and Gaussian basis set methodology (Gaussian and Plane Wave method, GPW) was employed to calculate the electronic structure. We used the PBE functional, with the Goedecker-Teter-Hutter pseudopotentials ${ }^{39}$ and a triple- $\zeta$ basis set with polarization functions (TZVP) ${ }^{40}$ augmented with the empirical Grimme's D2 correction. ${ }^{32}$ The cutoff for the plane wave basis was set to $400 \mathrm{Ry}$. AIMD simulations were run at $300 \mathrm{~K}$ in the NVT ensemble, using the Canonical Sampling through Velocity Rescaling (CSVR) thermostat. ${ }^{41}$ A time step of 0.5 fs was chosen. All simulations were equilibrated at $300 \mathrm{~K}$ with a more stringent thermostat (time constant: $10 \mathrm{fs}$ ) for about $1 \mathrm{ps}$ and then the production phase was run for at least $10 \mathrm{ps}$ with a more relaxed thermostat (time constant: $50 \mathrm{fs}$ ). Since $\mathrm{CP} 2 \mathrm{~K}$ requires $3 \mathrm{D}$ periodic systems, a value of $c=35$ $\AA$ was chosen to separate the slab replicas with enough vacuum. In all cases, only the superficial layer of the silica slab and the drug molecules were allowed to move.

\section{Characterization}

Samples were characterized by means of Fourier Transform Infrared spectroscopy (FTIR), nitrogen adsorption isotherms and thermogravimetry (TG) analysis. For FTIR measurements, powders were pressed in self-supporting wafers and spectra were recorded at room temperature with a Bruker Tensor 27 spectrometer operating at $2 \mathrm{~cm}^{-1}$ resolution, after outgassing the sample at $373 \mathrm{~K}$ for one hour (residual pressure equal to $0,1 \mathrm{~Pa}$ ). FTIR spectrum of crystalline $\mathrm{CTZ}$ was recorded on the powder dispersed in potassium bromide (KBr). FTIR spectrum of CTZ in solution was recorded on a diluted carbon tetrachloride $\left(\mathrm{CCl}_{4}\right)$ solution $\left(1 \mathrm{~g} \cdot \mathrm{L}^{-1}\right)$. Nitrogen adsorption isotherms were measured using a 
Quantachrome AUTOSORB-1 instrument after degassing at 373K for 2 hours. Brauner-EmmetTeller (BET) specific surface areas (SSA) were calculated in the relative pressure range 0,04-0,1 and the pore size distribution was determined through the NLDFT (Non Linear Density Functional Theory) method, using the NLDFT equilibrium model for cylindrical pores. ${ }^{42}$ TG analyses were carried out between $298 \mathrm{~K}$ and $1073 \mathrm{~K}$ in air (flow rate $100 \mathrm{~mL} \cdot \mathrm{min}^{-1}$ with a heating rate of $10 \mathrm{~K} \cdot \mathrm{min}^{-1}$ ) using a SETARAM 92 instrument to evaluate the quantity of incorporated drug. The desorption analysis were performed using a SETARAM 92 instrument following the procedure explained by Verevkin et al. ${ }^{43}$ and Price et al. ${ }^{44}$ Using the Clausius-Clapeyron relation, equation (1), the enthalpies of vaporization $\left(\Delta H_{v a p}\right)$ at the average temperature of investigation were obtained.

$\ln \left(\sqrt{T} \frac{d m}{d t}\right)=A+\frac{\Delta H_{v a p}}{R T}$

where $d m / d t$ is the mass loss rate at the specified temperature, $\mathrm{kg} \cdot \mathrm{s}^{-1} ; R$ is the universal gas constant, $\mathrm{J} \cdot \mathrm{mol}^{-1} \cdot \mathrm{K}^{-1}$ and $T$ is the temperature of the isothermal experiment, $\mathrm{K}$. Subsequently, vaporization enthalpies were reported to $298.15 \mathrm{~K}$ using a general methods of correction, reported by Chickos et al. (the Sidgwick's rule): ${ }^{45}$

$\Delta H_{\text {vap }}(298.15)=\Delta H_{v a p}(T)+0.0545(T-298.15)$

In equation (2), $T$ is the temperature of measurement or mean temperature of measurement if $\Delta H_{v a p}(T)$ has been obtained from a Clausius-Clapeyron treatment of vapor pressures. The experimental conditions used for the reliable determination of vaporization enthalpies of low volatile molecular compounds are following the references of Verevkin at al. ${ }^{43}$ A calibration curve with phenol has been done. The uncertainty of temperature calibration was less than $1 \mathrm{~K}$.

\section{RESULTS AND DISCUSSION}

\section{Clotrimazole: molecule and crystal}

CTZ was modeled both in gas phase and as a crystal, before studying its adsorption on amorphous silica. The starting point was the X-ray experimental structure by Song et al. ${ }^{46} \mathrm{CTZ}$ has a tetrahedral structure (Figure 1.a), with the central $s p^{3}$ carbon linked to two phenyl rings, one chlorophenyl ring 
and one imidazole ring. The CTZ molecule, optimized at PBE-D2 level of theory, is reported in Figure 1.b. The electrostatic potential mapped on the PBE electron density (Figure 1.c) clearly shows the nucleophilic character of the external nitrogen in the imidazole ring group, which is expected to behave as H-bond acceptor when interacting with the surface silanols. The rest of the molecule is generally apolar, as reflected by the experimentally measured low solubility in water (less than 0.01 $\left.\mathrm{g} \cdot \mathrm{L}^{-1}\right),{ }^{27}$ and is expected to engage in dispersive interactions with the silica surface.

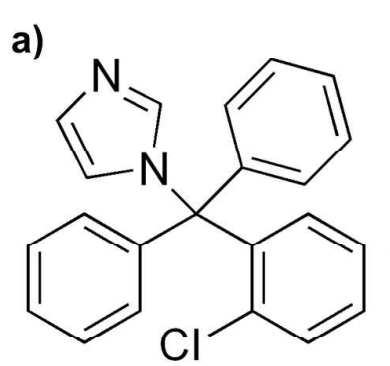

c)

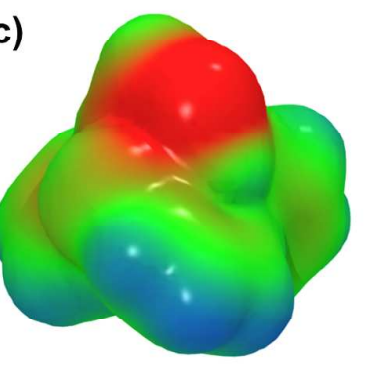

b)
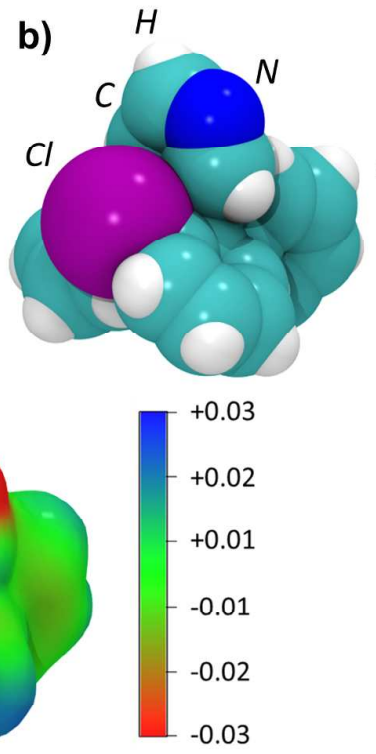

d) $a$

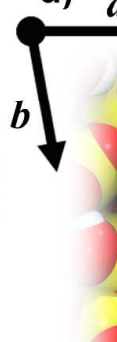

Figure 1. a) chemical structure of the $\mathrm{CTZ}$ molecule $\left(\mathrm{H}_{17} \mathrm{~N}_{2} \mathrm{C}_{22} \mathrm{Cl}\right)$. b) $3 \mathrm{D}$ space filling model of the CTZ tetrahedral structure with the three phenyl rings almost perpendicular to the imidazole ring. c) CTZ electrostatic potential mapped on the electron density showing the high electronegativity nature of the external nitrogen in the imidazole ring group. Blue, green and red colors correspond to positive, neutral, and negative values of the electrostatic potential (range values: $\mathrm{MIN}-0.03 \mathrm{au}$; MAX $+0.03 \mathrm{au}$.). d) top view of the amorphous silica surface model used in this paper, cell borders in black ( $a=12.6 \AA, b=12.8 \AA$ and $\left.\alpha=83.1^{\circ}, \mathrm{H}_{22} \mathrm{O}_{63} \mathrm{Si}_{26}\right)$.

The CTZ crystal has been optimized with and without Grimme's correction and compared to experimental results (Figure S1.a and Table S1, in Supporting Information). The structure is triclinic $(P \overline{1}$, $a=8.76 \AA, b=10.55 \AA, c=10.61 \AA$ and $\left.\alpha=114.1^{\circ}, \beta=97.0^{\circ}, \gamma=97.5^{\circ}\right)$ with two drug molecules per unit cell. If dispersion is not included in the calculation, the cell volume is overestimated by 
$+25.2 \%$, while inclusion of dispersive contributions lead to a cell contraction of $-8.4 \%$ with respect to single crystal X-ray data. ${ }^{46}$ The PBE-D2 cohesive energy of crystalline CTZ has been computed as $-146.5 \mathrm{~kJ} \cdot \mathrm{mol}^{-1}$ (Table 1) and, unsurprisingly, the interactions occurring in the crystal are dominated by dispersion $(78 \%)$. Indeed, the plain PBE cohesive energy is only $-31.8 \mathrm{~kJ} \cdot \mathrm{mol}^{-1}$. The corresponding $\Delta \mathrm{H}^{\mathrm{D}}$ at $298 \mathrm{~K}$, including dispersion (obtained from the full set of harmonic frequencies of the crystal), is $-131.7 \mathrm{~kJ} \cdot \mathrm{mol}^{-1}$.

Table 1. Energetics of the clotrimazole and MSU-H-CTZ systems

\begin{tabular}{|c|c|c|c|}
\hline system & $\Delta \mathrm{E}^{a}$ & $\Delta \mathrm{E}^{\mathrm{D} b}$ & $\Delta \mathrm{H}^{298 c}$ \\
\hline clotrimazole bulk $^{d}$ & -31.8 & -146.5 & -131.7 \\
\hline clotrimazole @ $(100)^{e}$ & - & -111.3 & -104.7 \\
\hline clotrimazole @ (010) & - & -124.5 & -117.1 \\
\hline clotrimazole @(001) & - & -118.9 & -111.9 \\
\hline imidazole (I) & -61.5 & -134.1 & -126.8 \\
\hline imidazole (II) & -58.4 & -102.6 & -99.1 \\
\hline phenyls (I) & -19.7 & -87.6 & -80.0 \\
\hline phenyls (II) & -12.3 & -78.4 & -73.6 \\
\hline molecular layer (I) & - & -117.1 & -101.7 \\
\hline molecular layer (II) & - & -116.8 & -99.5 \\
\hline CTZ bulk EXP. $\left(-\Delta H_{V}^{298}\right)^{g}$ & & & -91.6 \\
\hline CTZ incorporated EXP. $\left(-\Delta H_{V}{ }^{298}\right)^{n}$ & & & -91.8 \\
\hline
\end{tabular}

${ }^{a}$ Computed (only for selected systems) electronic interaction energy, without accounting for dispersion, corrected for BSSE. ${ }^{\mathrm{b}} \mathrm{As}{ }^{\mathrm{a}}$ including dispersion. ${ }^{\mathrm{c}}$ Computed enthalpy of adsorption (dispersion included), at $\mathrm{T}=$ $298 \mathrm{~K}$. ${ }^{\mathrm{d}}$ Cohesive energy of crystalline CTZ, computed with respect to a free molecule in gas phase. ${ }^{\mathrm{e}}$ Interaction of one CTZ molecule adsorbed on the (100), (010) and (001) faces of the CTZ crystal. ${ }^{\mathrm{f}} \mathrm{CTZ} /$ silica systems: for naming refer to Figure $2 .{ }^{\mathrm{g}}$ Experimentally measured vaporization enthalpy of CTZ bulk, extrapolated at $\mathrm{T}=298 \mathrm{~K} .{ }^{\mathrm{g}}$ Experimentally measured vaporization enthalpy of CTZ incorporated in MSU-H, extrapolated at $\mathrm{T}=298 \mathrm{~K}$. All values are in $\mathrm{kJ} \cdot \mathrm{mol}^{-1}$.

Experimentally, the lack of crystallization of CTZ inside mesoporous silica is observed. Furthermore, mesoporous materials are known to cause amorphization of crystalline drugs. This phenome- 
non has been described in literature both as a confinement effect ${ }^{47-50}$ and as a competition between crystal cohesion and adsorption on the silica surface..$^{23}$ To describe this competition, we have modelled the interaction of CTZ molecules with three crystalline surfaces of the same CTZ crystal. The three chosen surfaces were the (100), (010) and (001), which have been modeled through a periodic slab approach with a slab thickness equal to two unit cells. These surfaces represent the three main defect-free crystal faces and were optimized at the PBE-D2 level. The surface energies were 0.10, 0.11 and $0.09 \mathrm{~J} \mathrm{~m}^{-2}$, respectively. The adsorption of CTZ on the three crystal surfaces has been simulated by adding one drug molecule in interaction with the slab in the same position occupied in the bulk structure and re-optimizing the structure (Figure S1.b in Supporting Information). The added CTZ molecule maximizes the contact with the surface molecules mainly through dispersion and electrostatics interactions. These are in particular $\pi-\pi$ edge to face interactions of phenyls and chlorophenyls. Other $\pi-\pi$ interactions (e.g. face to face) are not present due to steric hindrance and rigidity of the molecule. Table 1 reports the computed interaction energies of CTZ on the three crystal surfaces together with the corresponding enthalpies at $298 \mathrm{~K}$. Unsurprisingly, the interaction energies of CTZ with its crystal surfaces are comparable to each other with an average value of $-113 \mathrm{~kJ}^{\mathrm{mol}}{ }^{-1}$, lower than the crystal cohesive energy $\left(-132 \mathrm{~kJ} \mathrm{~mol}^{-1}\right)$ due to the reduced number of intermolecular interactions of the adsorbed drug with the surface compared to those in the bulk.

TG desorption analysis of crystalline CTZ (Table 1) shows an experimental enthalpy of vaporization of about $92 \mathrm{~kJ} \cdot \mathrm{mol}^{-1}$, reasonably close to the theoretical values. The comparison between computed and experimental cohesive energy for the CTZ crystal shows some overestimation due to the PBED2 method. We proved in the past that the same applies to B3LYP-D2 in the case of molecular crystals and we proposed a slightly different formulation known as B3LYP-D2* which brings computed cohesive energy in better agreement with the experiment. Unfortunately this correction is not available for PBE-D2 so that we should be aware of a somehow systematic overestimation of the computed data also for the interaction with the surface. ${ }^{51}$ 


\section{Clotrimazole adsorption on the silica pore wall}

Experimentally, CTZ was loaded into MSU-H through $\mathrm{scCO}_{2}$, achieving a maximum drug loading of $34 \%$ by mass (vide infra).

In the simulations, CTZ was adsorbed on a silica surface model described in a previous study by some of us $^{52}$ and already employed to simulate the adsorption of ibuprofen and aspirin. ${ }^{23}$ The use of a flat surface in the present work, at variance with an explicit model of MSU-H, is justified by the curvature of the MSU-H pore, whose diameter $(8.5 \mathrm{~nm})$ is much larger than the CTZ molecule: indeed, a flat surface model represents a very good approximation of what the drug is "seeing" inside the pores. This surface is represented in Figure 1.d and exhibits a silanol density of $4.5 \mathrm{OH} \cdot \mathrm{nm}^{-2}$, close to the experimentally measured value for fully hydroxylated surfaces $\left(4.9 \mathrm{OH} \cdot \mathrm{nm}^{-2}\right){ }^{53}$ The silica surface model contains 111 atoms in the unit cell $\left(a=12.6 \AA, b=12.8 \AA\right.$ and $\alpha=83.1^{\circ}$, cell composition: $\mathrm{H}_{22} \mathrm{O}_{63} \mathrm{Si}_{26}$ ). The surface exposes eight silanols per the unit cell. Of these, only one is free, while the others are interacting through H-bonds. Particularly, three SiOHs cooperates in forming a stable H-bonded chain.

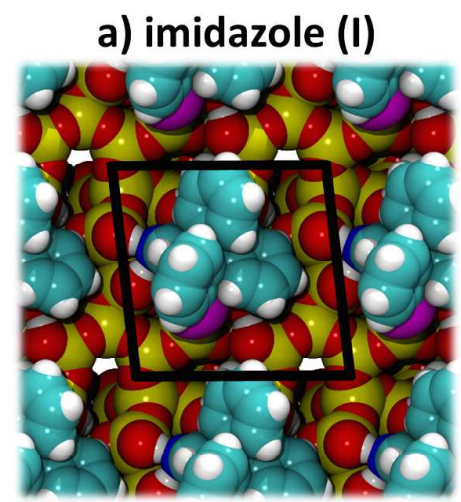

c) phenyls (I)

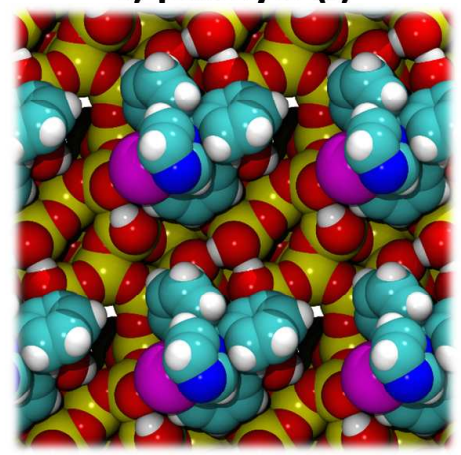

b) imidazole (II)

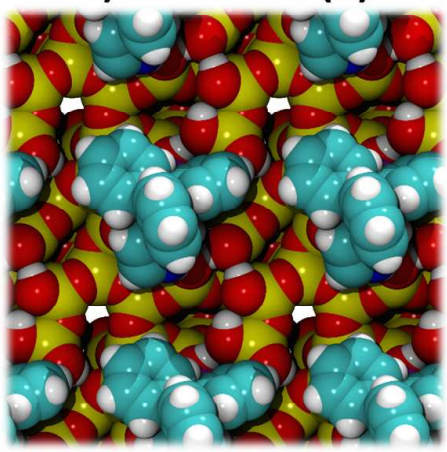

d) phenyls (II)

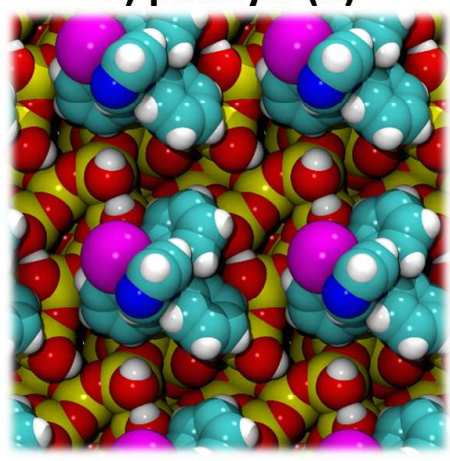

e) molecular layer (I)

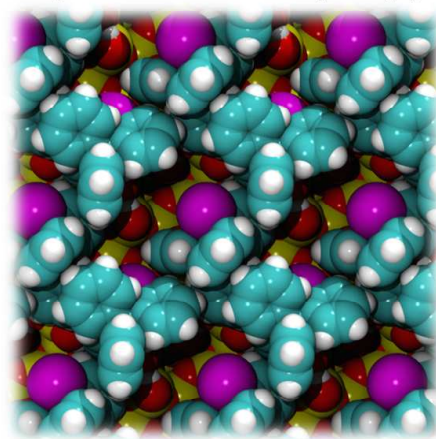

f) molecular layer (II)

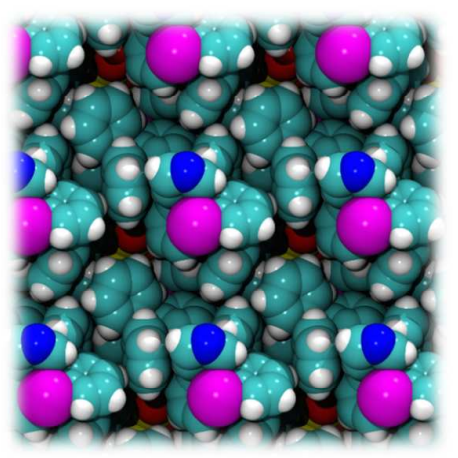


Figure 2. View along the $\mathrm{z}$ axis of the fully optimized six different geometries of adsorption. a) imidazole (I): Imidazole ring pinched by two silanols; this structure started as chlorine interacting with a silanol, and evolved in a shifted position during geometry optimization, due to the high H-bond acceptor character affinity of imidazole's nitrogen. b) imidazole (II): imidazole ring interacting with one ending chain silanol. c) phenyls (I): phenyl rings relating with silanols and one SiOH-Cl weak H-Bond. d) phenyls (II): phenyl rings interacting with silanols. e) molecular layer (I): two molecules per silica unit cell. f) molecular layer (II): three molecule per unit cell.

CTZ was manually docked on the surface, aiming at maximizing the interactions between exposed silanols and the different drug's functional groups. In order to match the experimental conditions, six main starting geometries have been studied. Four of them are characterized by one molecule per silica unit cell (drug loading $\sim 13 \%$ by mass), while the other two simulate a molecular layer as observed in previous results ${ }^{15}$ with two and three molecules per unit cell (drug loading $\sim 27 \%$ and $\sim 41 \%$ by mass, respectively). All models are shown in top view in Figure 2: a) imidazole (I) and b) imidazole (II) are structures with CTZ interacting through its imidazole ring, while in c) phenyls (I) and d) phenyls (II) the molecule is adsorbed through its apolar portion; e) molecular layer (I) and f) molecular layer (II) are the highest loading structures. The 13\% loading models (a-d) have been optimized both with and without Grimme's dispersion correction to measure the role of dispersion, while for the high loadings only PBE-D2 has been used.

\section{Interactions between clotrimazole and the silica pore wall}

Figure 3 reports the main types of interaction between CTZ and silanols as resulted from the simulations. Both the imidazole ring and the chlorophenyl group of CTZ can be involved in H-bonds with the surface hydroxyls (Figure 3.a-c) but silanol- $\pi$ bonds interactions are also established (Figure 3.d).

The imidazole ring can form both two (Figure 3.a) and one (Figure 3.b) H-bonds with the surface. In the first case (observed only in the imidazole (I) structure) the imidazole's nitrogen is pinched between two silanols and the two H-bonds have the same length (1.84 $\AA$, for the imidazole (I) case), 
suggesting an equivalency of the two interactions. In most cases, however (imidazole (II) and in the molecular layer geometries), CTZ forms only one H-bond through its imidazole ring, usually with the terminal silanol of an H-bonded chain, since these terminal groups are known to be good H-bond donors due to their increased acidity. ${ }^{22,23,25}$ Notably, the H-bond length in the imidazole (II) case $(1.51 \AA)$ is shorter (and the interaction stronger) than in the imidazole (I) situation $(1.84 \AA)$.

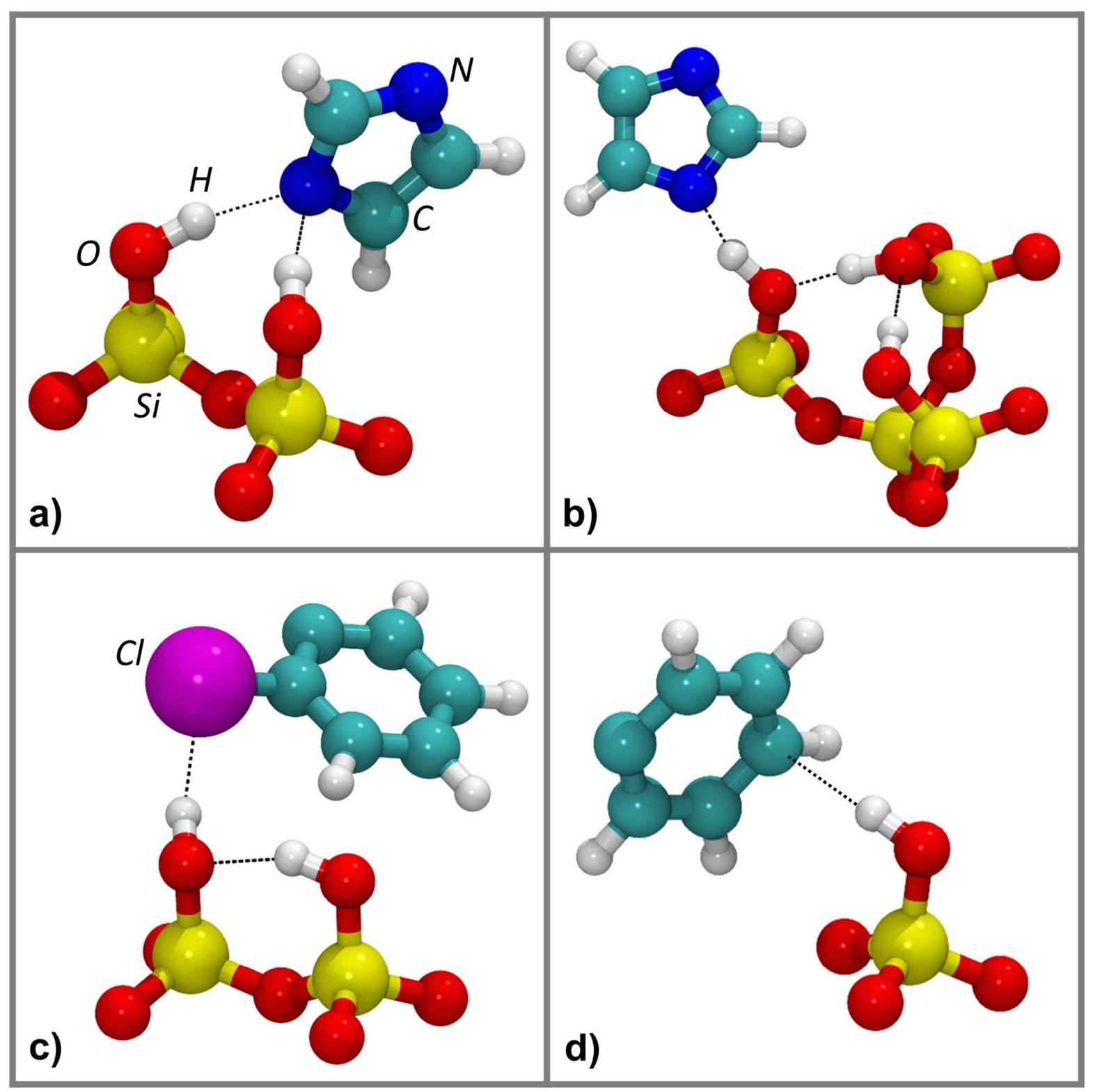

Figure 3. Types of interactions: a) Imidazole-CTZ double H-bonds (extracted from the imidazole (I) structure). b) Imidazole-CTZ single H-bond (extracted from the imidazole (II) structure). c) Chlorophenyl-CTZ interaction (extracted from the phenyls (I) structure). d) $\mathrm{SiOH}-\pi$ interaction (extracted from the phenyls (II) 
structure).

In agreement with previous results for other more polar drugs ${ }^{23}$, the pattern of mutual H-bonds between surface silanols is restructured in response to the approach of molecules rich of H-bond donors/acceptors functional groups. This feature is present in all the explored dockings. For instance, in the imidazole (I) case (represented in the local view of Figure 3.a) originally the two silanols were interacting with each other. Since an H-bond interaction between vicinal silanols is known to be quite weak, ${ }^{22}$ this mutual interaction is easily broken by the incoming CTZ molecule. On the other hand, in cases that include an interaction as reported in Figure 3.b, the effect is more subtle: the Hbond with $\mathrm{CTZ}$ is able to enhance the interactions towards the imidazole ring along the whole silanol chain.

H-bonds of the Si-O-H---Cl type (Figure 3.c) are weaker than those with imidazole $(2.24 \AA$ in the phenyls (I) case). Interestingly, in phenyls (I) the distance between the two SiOHs is not perturbed by the new interaction.

Several SiOH- $\pi$ (surface-CTZ, Figure 3.d) have been observed in almost all the different structures, while $\pi-\pi$ edge to face lateral interactions (CTZ-CTZ) characterize the molecular layer models. The mean value of $\mathrm{SiOH}-\pi$ bonds is $2.10 \AA$ and accordingly to Tsuzuki et al. ${ }^{54}$ the $\pi-\pi$ bonds have a mean value of $4.60 \AA$. Comparing bond lengths in the different models, we suggest that $\mathrm{SiOH}-\pi$ interactions are half way between $\mathrm{SiOH}-\mathrm{N}$ and $\mathrm{SiOH}-\mathrm{Cl} \mathrm{H}-$ bonds, as regards interaction strength.

\section{Energetics of the clotrimazole-silica interaction}

Table 1 reports the computed interaction energies with $\left(\Delta \mathrm{E}^{\mathrm{D}}\right)$ and without $(\Delta \mathrm{E})$ dispersion (when available) and the adsorption enthalpies at standard temperature $\left(\Delta \mathrm{H}^{298}\right)$, including dispersion.

All simulations reveal that the adsorption of CTZ on amorphous silica is a strongly exothermic process. Nevertheless, different geometries and consequently interaction types correspond to different energies of adsorption, ranging from $-134.1 \mathrm{~kJ} \cdot \mathrm{mol}^{-1}$ for the imidazole (I) case to $-78.4 \mathrm{~kJ} \cdot \mathrm{mol}^{-1}$ for 
the phenyls (II) geometry.

Comparing $\Delta \mathrm{E}$ and $\Delta \mathrm{E}^{\mathrm{D}}$, London forces constitute the predominant contribution to the interaction in all systems, except for the imidazole (I) case. Of particular interest are the phenyls (I) and (II) structures: in these cases the interaction energies without dispersion are small, while including vdW interactions increases these energies by more than +400 and $+600 \%$, respectively. Dispersion plays a more important role in CTZ adsorption on hydrophilic silica than it has been reported for more polar drugs such as ibuprofen and aspirin. ${ }^{23,25}$ For the molecular layer geometries, the average interaction energies (and enthalpies) per molecule have very similar values despite the fact that the third additional molecule in the molecular layer (II) is not involved in H-bonds with the surface. This is a further evidence that, for an apolar molecule, the lateral self-interaction (dispersion-driven) is similar to that of the molecule with the surface. In all cases the CTZ deformation energies are negligible due to the rigidity of the molecule with a mean value of $7 \mathrm{~kJ} \cdot \mathrm{mol}^{-1}$.

Table 1 reveals that all the computed interaction energies and enthalpies are close to each other, enlightening a possible competition between crystalline and adsorbed CTZ. Assuming that the supercritical incorporation is a step route controlled by dissolution and adsorption of single molecules, this process is almost isoenergetic, since for each adsorption on silica an average of $110 \mathrm{~kJ} \cdot \mathrm{mol}^{-1}$ are gained and for each desorption from the crystal $115 \mathrm{~kJ} \cdot \mathrm{mol}^{-1}$ are lost. This could be the explanation of the lack of crystallization in pores smaller than 20 times the molecule diameter explained by Sliwinska-Bartkowiak et al. ${ }^{47}$ and observed by other authors. ${ }^{48-50}$

TG desorption analysis of CTZ in MSU-H (34\% by mass) produces an enthalpy of vaporization of 91.6 $\mathrm{kJ} \cdot \mathrm{mol}^{-1}$ as reported in Table 1. As abovementioned (and also reported in Table 1), a similar analysis on crystalline CTZ results in a value of $91.8 \mathrm{~kJ} \cdot \mathrm{mol}^{-1}$. Thus, also the experimental data suggest that the two processes are almost isoenergetic, supporting the hypothesis on silica-induced drug amorphization.

The experimental enthalpy of vaporization for the MSU-H-CTZ case is very close (in absolute value) to the computed adsorption enthalpies for both $\mathrm{CTZ}$ molecular layers $\left(-101 \mathrm{~kJ} \cdot \mathrm{mol}^{-1}\right)$. The com- 
parison of the experimental value $\left(91.6 \mathrm{~kJ} \cdot \mathrm{mol}^{-1}\right)$ with the data obtained for the different low loading geometries suggests which interaction reported in Figure 3 is more represented in the real sample. The closest value is obtained for the imidazole (II) case, i.e. adsorption driven by one H-bond between the imidazole group and a surface silanol. On the other hand, situations like imidazole (I), although theoretically very stable, seem to be rarer events in the real material due to the lower hydrophilicity of the experimental silica, the steric hindrance of the molecules and the low configurational entropy content of this unique configuration. Interestingly, the computed interaction enthalpy of the phenyls (I) model is also quite close to the experimental value, suggesting that phenyls-driven interactions may be present in a significant portion of the adsorbed CTZ population. In summary, all configurations of Figure 3.a-d are probably represented in the real sample, since their average $\Delta \mathrm{H}^{\mathrm{D}}(-$ $\left.94.9 \mathrm{~kJ} \cdot \mathrm{mol}^{-1}\right)$ is very close to the experimental measure.

\section{Model of adsorption: nitrogen adsorption and TG analysis}

Experimental $\mathrm{N}_{2}$ adsorption isotherms (Figure S2.a in Supporting Information), through Non Linear Density Functional Theory (NLDFT), allow the calculation of the experimental pore size distributions (PSDs) before and after the $\mathrm{scCO} 2$ incorporation of $\mathrm{CTZ}$. The results are reported in Figure 4.a. As expected, drug incorporation reduces the pore diameter from the $86 \AA$ value of bare MSU-H (black line) to a lower value of $67 \AA$ (blue line). 
a)

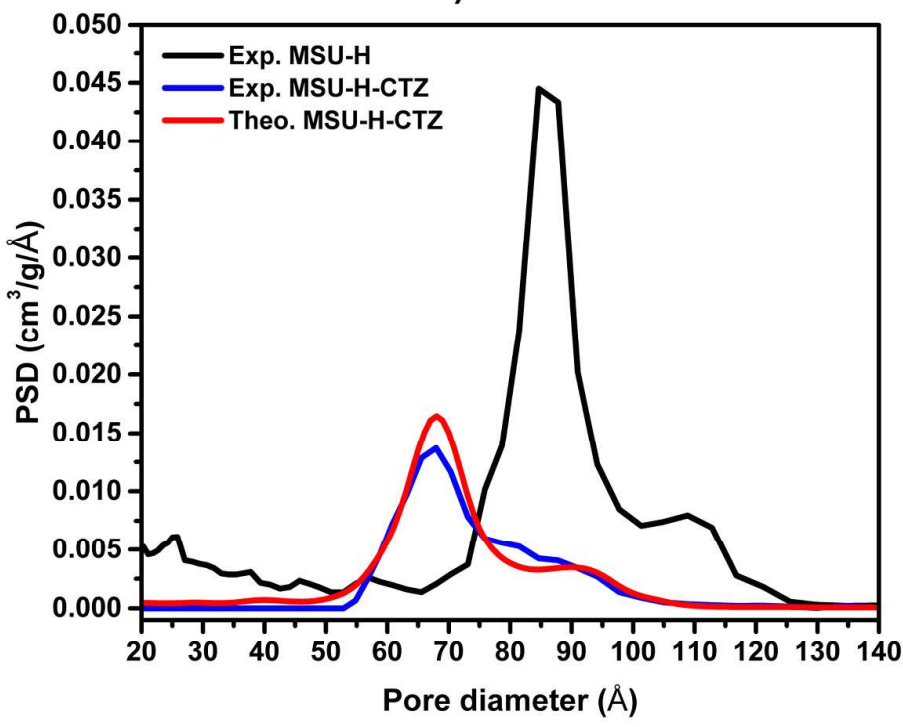

b)
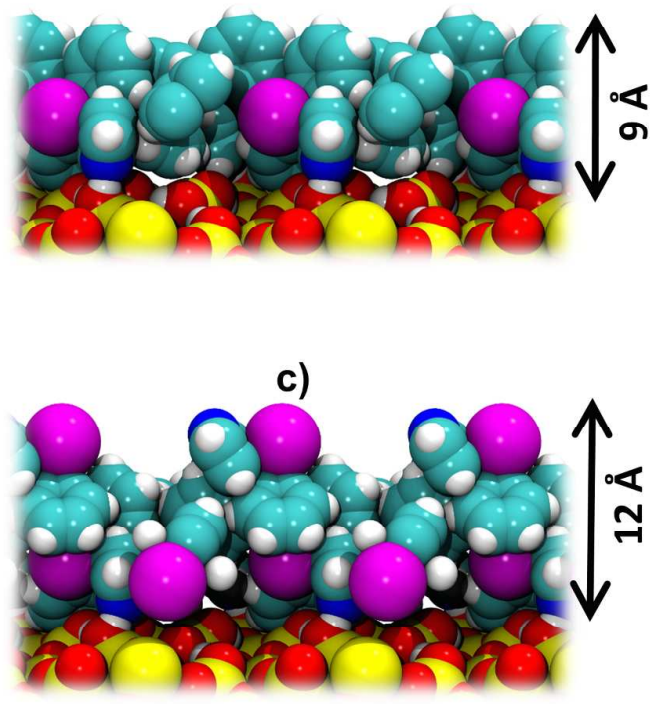

Figure 4. Adsorption model. a) Comparison of Pore Size Distributions (PSDs) as calculated from the two molecular layer models (red) and as measured before (black) and after (blue) the $\mathrm{scCO}_{2}$ incorporation. b) and c) side views along the $a$ direction of molecular layers (I) and (II), respectively.

As already described in a previous work by some of us, ${ }^{15}$ the drug can be assumed as adsorbed mainly in the form of a molecular layer. Using a bare value of thicknesses of the single molecular layers I and II (Figure 4.b-c), the corresponding new PSDs can be calculated (Figure S2.b). Clearly, with this approach, the calculated PSDs are unable to describe the experimental results.

On the other hand, experimental TG analysis reports an incorporated quantity of $34 \%$ by mass, which is in between the loading calculated for layer (I) and layer (II), which are $\sim 27 \%$ and $\sim 41 \%$ by mass, respectively. By calculating the experimental planar concentration of CTZ (molecules per $\mathrm{nm}^{2}$ ) and comparing it to our theoretical models of molecular layers (2 CTZs/cell, Figure 2.e and 3 CTZs/cell, Figure 2.f), it is shown that the real system can be described by a 50:50 mixture of the two molecular layer geometries. Indeed, the unit cell of the simulated silica surface has an area of $1.6 \mathrm{~nm}^{2}$ and the experiment reports $2.5 \mathrm{CTZ}$ molecules per $1.6 \mathrm{~nm}^{2}$. As a consequence, a simulated MSU-H-CTZ PSD has to be calculated, starting from the experimental PSD of bare MSU-H, assuming thicknesses representative of both the molecular layer (I) and (II) models. These thicknesses have been evaluated following the Connolly surfaces ${ }^{55}$ before and after CTZ adsorption of the computed 
models, with the purpose to take into account the vdW molecular volume and the roughness generated by the statistical distribution of 2 and $3 \mathrm{CTZ}$ molecules per $1.6 \mathrm{~nm}^{2}$. Therefore, the molecular layer surfaces have been discretized in 677 squares $\left(0.25 \AA^{2}\right)$ in order to evaluate the thicknesses, for each point, between the starting silica model and the molecular layers. Subsequently, a new PSD has been calculated for each couple of evaluated thicknesses and all curves have been combined together in the final theoretical PSD of Figure 4.a (red). Such procedure results in an impressive agreement between simulation and experiment, validating the data interpretation.

\section{Mobility of adsorbed clotrimazole}

Ab-Initio Molecular Dynamics (AIMD) has been performed on the different statically optimized geometries in order to evaluate the stability of the local minimum structures of Figure 2. In Figure 5 the Root Mean Square Deviations (RMSD) of the atomic positions, during the production, with respect to the first frame, are reported for the four AIMD simulations (imidazole (I), phenyls (I), phenyls (II) and molecular layer (II)). RMSDs are separated in the CTZ and silica contributions. In all cases, the mobility of the adsorbed drugs is higher than that of the silica surface. The latter seems equilibrated during all simulations. 

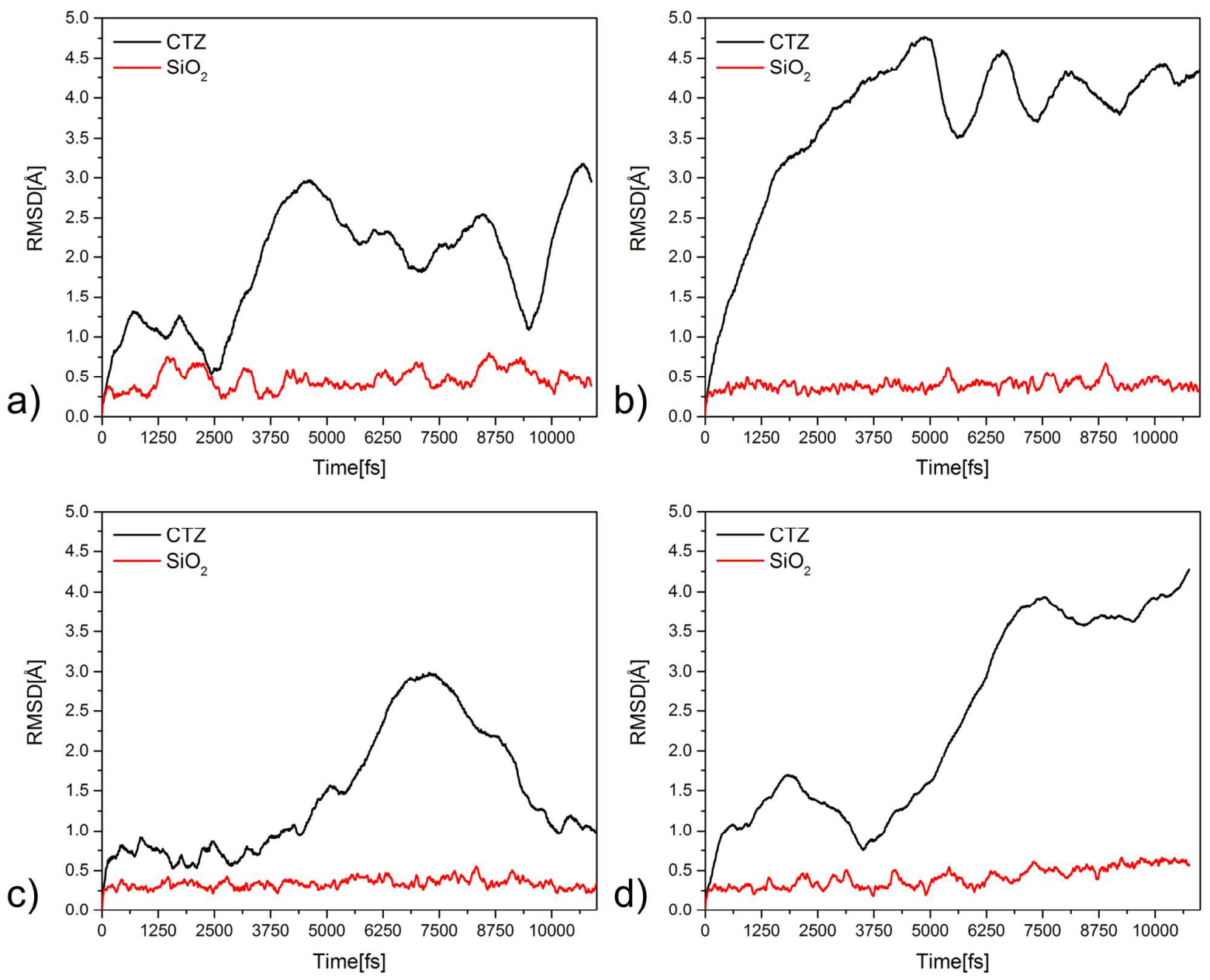

Figure 5. Silica $\left(\mathrm{SiO}_{2}\right)$ and clotrimazole (CTZ) RMSD (in $\AA$ ) with respect to the initial structure for all AIMD simulations. For the silica surface, only the atoms free to move in the simulation have been considered. a) imidazole (I); b) phenyls (I); c) phenyls (II); d) molecular layer (II). See Figure 3 for the corresponding structural details.

The imidazole (I) structure, which is the most stable configuration of CTZ on silica according to Table 1, shows a general stability of the adsorbed molecule during the 11 ps simulation. Although Figure 5.a reports a significant $\mathrm{CTZ}$ mobility, the molecule fluctuates around the initial adsorption geometry, without evolving into a new configuration. As reported in Figure S3 in Supporting Information, while equivalent H-bond interactions were present in the static model (Figure 3.a), during the AIMD one H-bond remains stable while the second one shows instability: in many points during the time evolution the interaction is lost and the silanol is free to rotate as shown by small bumps in the $\mathrm{SiO}_{2} \mathrm{RMSD}$. However, this interaction is always recovered after a certain time proving its rele- 
vance at room temperature, although the two H-bonds are not really equivalent, as resulting from static simulations.

a)

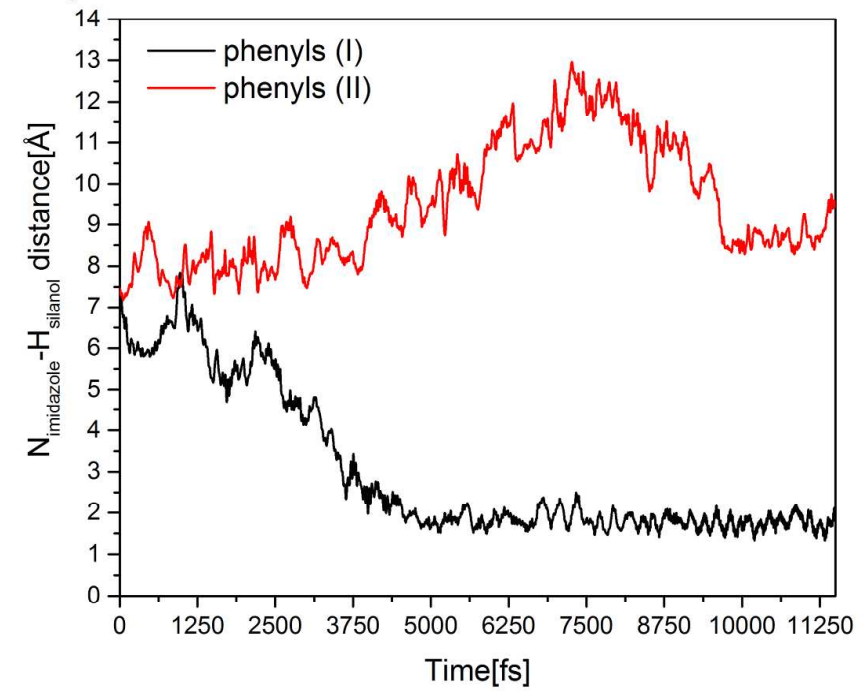

b)

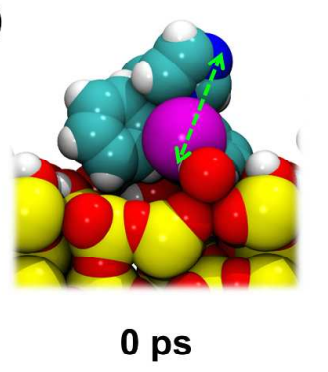

c)

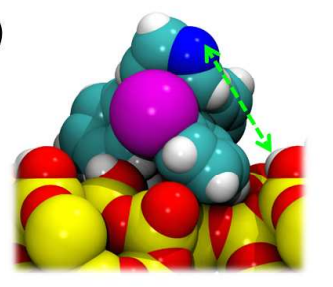

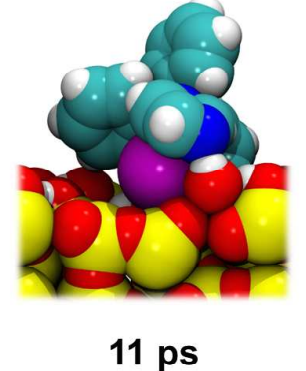

11 ps

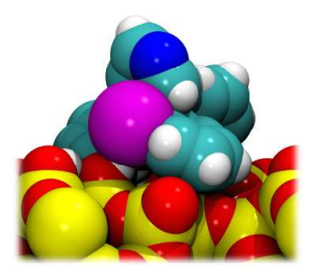

Figure 6. AIMD of phenyls (I) and (II): a) exposed nitrogen - SiOH distance over time: phenyls (I) in red, phenyls (II) black. b) 3D space filling models of phenyls (I) at 0 and $11 \mathrm{ps}$. c) 3D space filling model of phenyls (II) at 0 and 11 ps. The nitrogen $-\mathrm{SiOH}$ distance plotted in the graph is highlighted in green.

On the contrary, the phenyls (I) structure proved to be unstable at room temperature. The RMSD computed along this AIMD simulation (Figure 5.b) shows the very high mobility of the drug (the highest among all considered cases) on an otherwise equilibrated surface. Particularly, CTZ departs from the initial configuration to reach a new equilibrium about 4 ps later. Figure 6.a traces this movement by plotting the distance between the exposed imidazole's nitrogen and a surface $\mathrm{SiOH}$ against time (black line), while Figure 6.b shows the starting and ending structures: the initially present chlorine-silanol interaction is immediately lost and the molecule rotates in order to establish a new SiOH-imidazole H-bond. This new interaction (average length: $1.80 \AA$ ) is formed within the first 4 ps and kept until the end of the simulation. This complex process, involving a movement of the whole molecule, appears almost barrierless, being observable in a very short time scale, suggesting that the phenyls (I) configuration transforms rapidly in a more stable imidazole (II) geometry, if 
the surface morphology allows for it. The new geometry, Figure 6.b (right), was re-optimized and the corresponding interaction energy $\left(\Delta \mathrm{E}^{\mathrm{D}}\right)$ was computed as $-106 \mathrm{~kJ} \cdot \mathrm{mol}^{-1}$ with respect to the initial value of $-88 \mathrm{~kJ} \cdot \mathrm{mol}^{-1}$, meaning that the system was able to evolve autonomously to a more stable configuration.

To see whether such instability is a common feature of phenyls-driven adsorptions, an AIMD simulation on the phenyls (II) structure has been performed. Along the 11 ps simulation, this model was unable to rotate and the CTZ's RMSD (Figure 5.c) reveals a much higher stability than the phenyls (I) case. As can be also noticed from the starting and ending point of the simulation (Figure 6.c), the molecule simply fluctuates around the initial position. The plot in time of the same imidazole-SiOH distance adopted for the phenyls (I) simulation (Figure 6.a, red line) shows that no new H-bond interaction is formed and the imidazole ring remains unbound. These results suggest that dispersive forces and $\mathrm{SiOH}-\pi$ interactions are able alone to preserve the phenyls (II) geometry at room temperature. The AIMD simulations on the phenyls structures show that, at least in part of the cases, if an incoming CTZ molecule adsorbs on silica through its phenyl rings it may keep this configuration without forming imidazole interactions, although such structure is thermodynamically less stable. This further supports the explanation of TG desorption data (vide supra).

\section{Molecular layer adsorption}

AIMD simulation on the molecular layer (II) structure shows high mobility of the three CTZs (per unit cell) on the surface. The RMSD of the atomic positions along the AIMD simulation (Figure 5.d) shows a large movement between 4 and 7 ps that results in a new configuration, with a RMSD value of $4.3 \AA$ with respect to the starting CTZ conformation after 11 ps. The process is described in Figure 7, where the exposed nitrogen atoms of the imidazole rings of the three adsorbed molecules in each unit cell are referred as N1, N2 and N3. In the starting configuration (Figure 7.b, case A, and Figure 7.c, left), one CTZ molecule is H-bonded through its imidazole's nitrogen (N1) to the terminal silanol of a chain made up of three silanols, here referred as SiOH_I, SiOH_II, SiOH_III. The 11 
ps of AIMD result in a global shift of the adsorbed molecular layer, as reported in Figure 7.c, taking as reference the unit cell borders. The driving force for this phenomenon is the loss of the N1SiOH_III H-bond, Figure 7.b (case B), with the concurrent N1-SiOH_I H-bond formation, through a flip of the whole silanol chain. The graph in Figure 7.a, reporting the N1-SiOH_III and N1-SiOH_I distances, clearly shows a transition state where the chain is lost and the imidazole's nitrogen (N1) is equidistant from $\mathrm{SiOH}(\mathrm{I})$ and (III). Looking at the potential energy fluctuations during this simulation (Figure S4 in Supporting Information), we estimate, in a very approximate way, the electronic activation energy of this process as $29.7 \mathrm{~kJ} \cdot \mathrm{mol}^{-1}$ that can be considered an upper limit for the real value. The new computed interaction energy $\Delta \mathrm{E}^{\mathrm{D}}$, after optimizing the final point of the AIMD simulation, is $-130 \mathrm{~kJ} \cdot \mathrm{mol}^{-1}$ and the contribution for the silica deformation, due to the flip of the silanols chain, is $+44 \mathrm{~kJ} \cdot \mathrm{mol}^{-1}$. 
a)
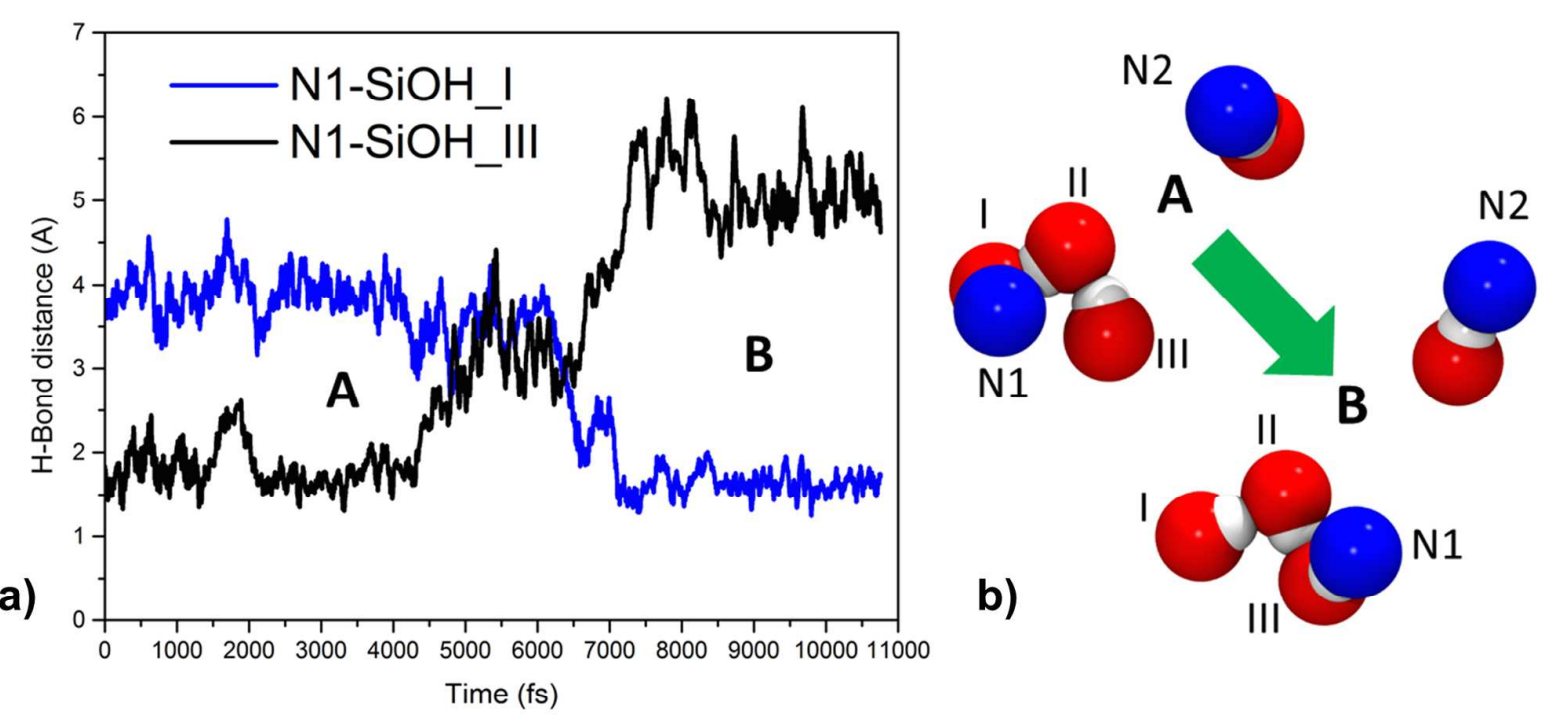

c)
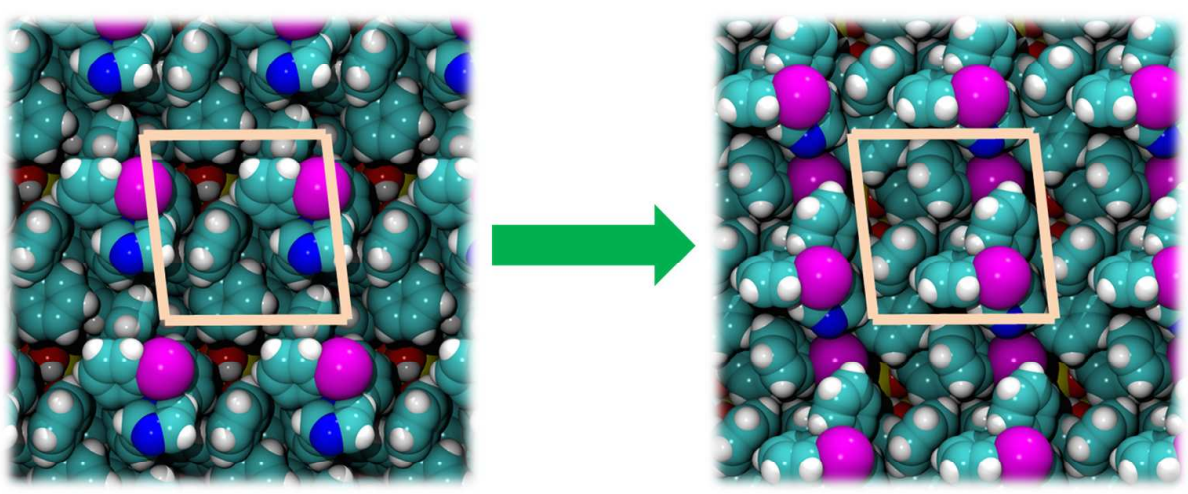

0 ps $(\Delta E=-117)$

Figure 7. AIMD of the molecular layer (II) structure: a) N1-SiOH(I) and N1-SiOH(III) bond distances in time. b) starting (A) and final (B) positions of N1 and N2 with respect to the involved SiOHs. c) Top views of the initial (left) and final (right) configurations in the AIMD simulation, with the corresponding interaction energies per $\mathrm{CTZ}$ molecule $\left(\mathrm{kJ} \cdot \mathrm{mol}^{-1}\right)$; cell borders in pink.

These AIMD results are in accordance with the experimental finding of a "liquid like" behavior of ibuprofen adsorbed in MCM-41. ${ }^{18,19}$ Considering that CTZ is much more hydrophobic than ibuprofen it is no surprise that CTZ molecular layers are very mobile, despite the significant underneath interactions. This mobility can be represented as a walking step process guided by local changes in the H-bond interactions, helped by a high flexibility of the silica surface silanols.

\section{Experimental and theoretical FT-IR interpretation}

Experimental and theoretical vibrational spectra of CTZ in molecular, crystalline and adsorbed envi- 
ronments have been obtained (Figure S5 in Supporting Information). Table S2 in Supporting Information reports a complete assignment of CTZ vibrational frequencies, characterized by three main areas of interest: aromatic $(\mathrm{C}-\mathrm{H})$ stretching region $\left(3000-3250 \mathrm{~cm}^{-1}\right)$, aromatic $(\mathrm{C}=\mathrm{C}, \mathrm{C}=\mathrm{N})$ stretching bands $\left(1300-1600 \mathrm{~cm}^{-1}\right)$ and aromatic $(\mathrm{C}-\mathrm{H})$ bending peaks $\left(800-600 \mathrm{~cm}^{-1}\right)$.

Figures 8 and 9 report both the experimental (blue line) and the theoretical (red line) IR spectra of CTZ in interaction with silica at low and high coverage. The low coverage experimental spectrum has been acquired on a MSU-H-CTZ sample with a drug loading of $18 \%$ by mass, while the high coverage corresponds to a drug loading of $34 \%$ by mass. As regards the simulated spectra, the CTZ modes have been obtained in both cases from a vibrational analysis in the harmonic approximation of the drug in the four single molecule configurations (Figure 2.a-d), combined by Boltzmann weighting their contribution to the infrared intensity according to the computed interaction energies. These modes were corrected for anharmonicity, using a 0.960 scaling factor. The theoretical SiO-H stretching mode contributions for the low coverage spectrum (Figure 8) were obtained from the four single molecule geometries (Figure 2.a-d) plus the new configuration of phenyls (I) after AIMD. For the high coverage spectrum (Figure 9), they were obtained from the two molecular layer structures (Figure 2.e-f) plus the new configuration of molecular layer (II) after AIMD. In all cases, the SiO-H stretching modes have been corrected with the Pimentel's empirical rule to account for the broadening effect due to H-bonding. ${ }^{56}$ The uncorrected computed SiO-H frequencies have been reported in the lower part of both Figure 8 and 9 as vertical lines. The final theoretical spectra (red lines) of Figure 8 and 9 are then the combination of these $\mathrm{SiO}-\mathrm{H}$ stretching modes and the $\mathrm{CTZ}$ signals. Figure 8 also includes the theoretical spectra computed for the four low loading configurations, limited to the SiO-H stretching modes. 


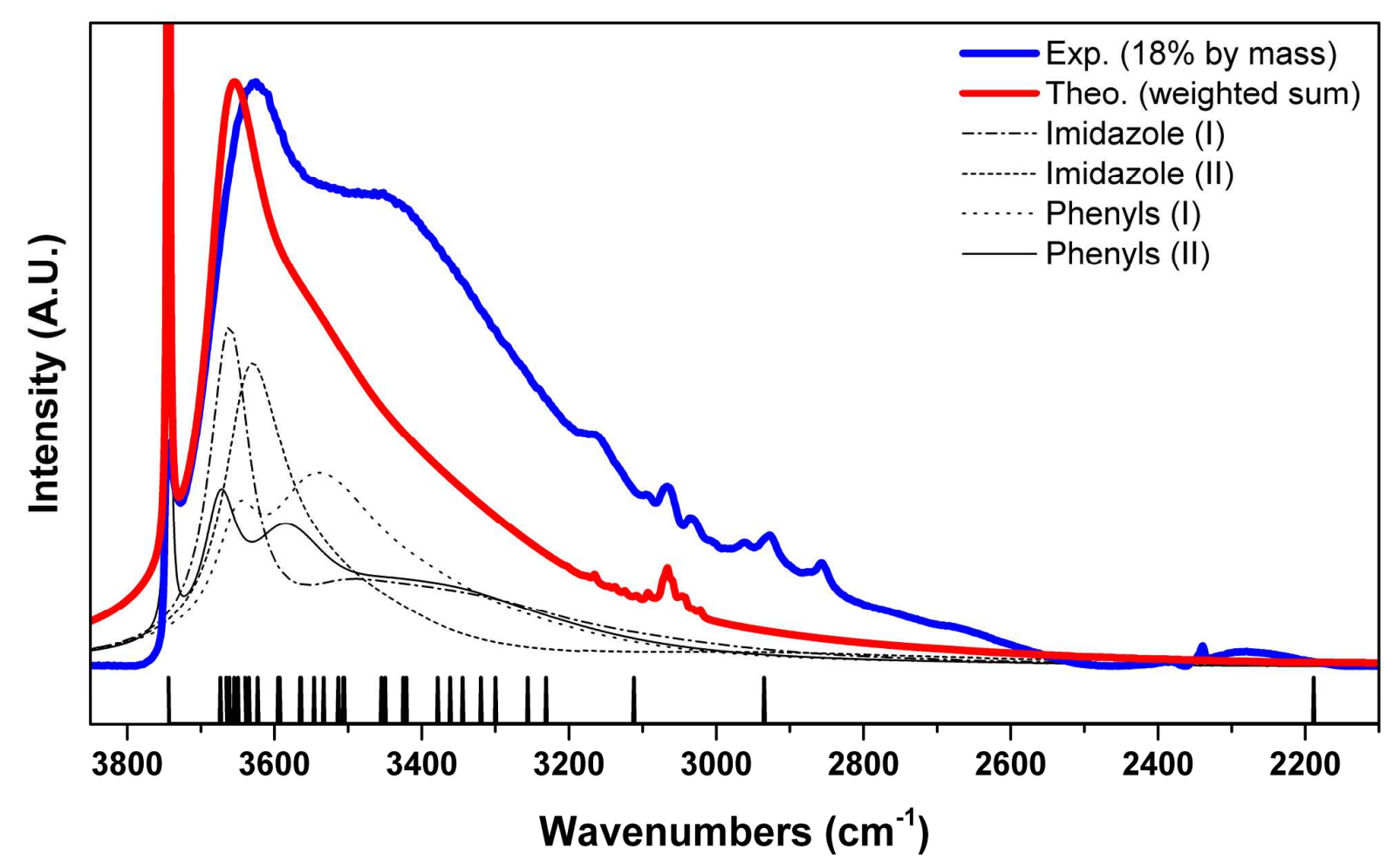

Figure 8. Experimental and simulated IR: experimental FTIR spectrum of MSU-H-CTZ at $18 \%$ by mass (blue); theoretical IR spectrum of CTZ combined with $\mathrm{SiOH}$ vibrational contribution (red); simulated IR spectrum of $\mathrm{SiOH}$ vibrational contribution of: imidazole (I) (dot-dashed black line); imidazole (II) (dashed black line); phenyls (I) (dotted black line); phenyls (II) (black line). At the bottom of the graph, sticks represent the theoretical $\mathrm{SiO}-\mathrm{H}$ stretching frequencies without Pimentel's correction. 


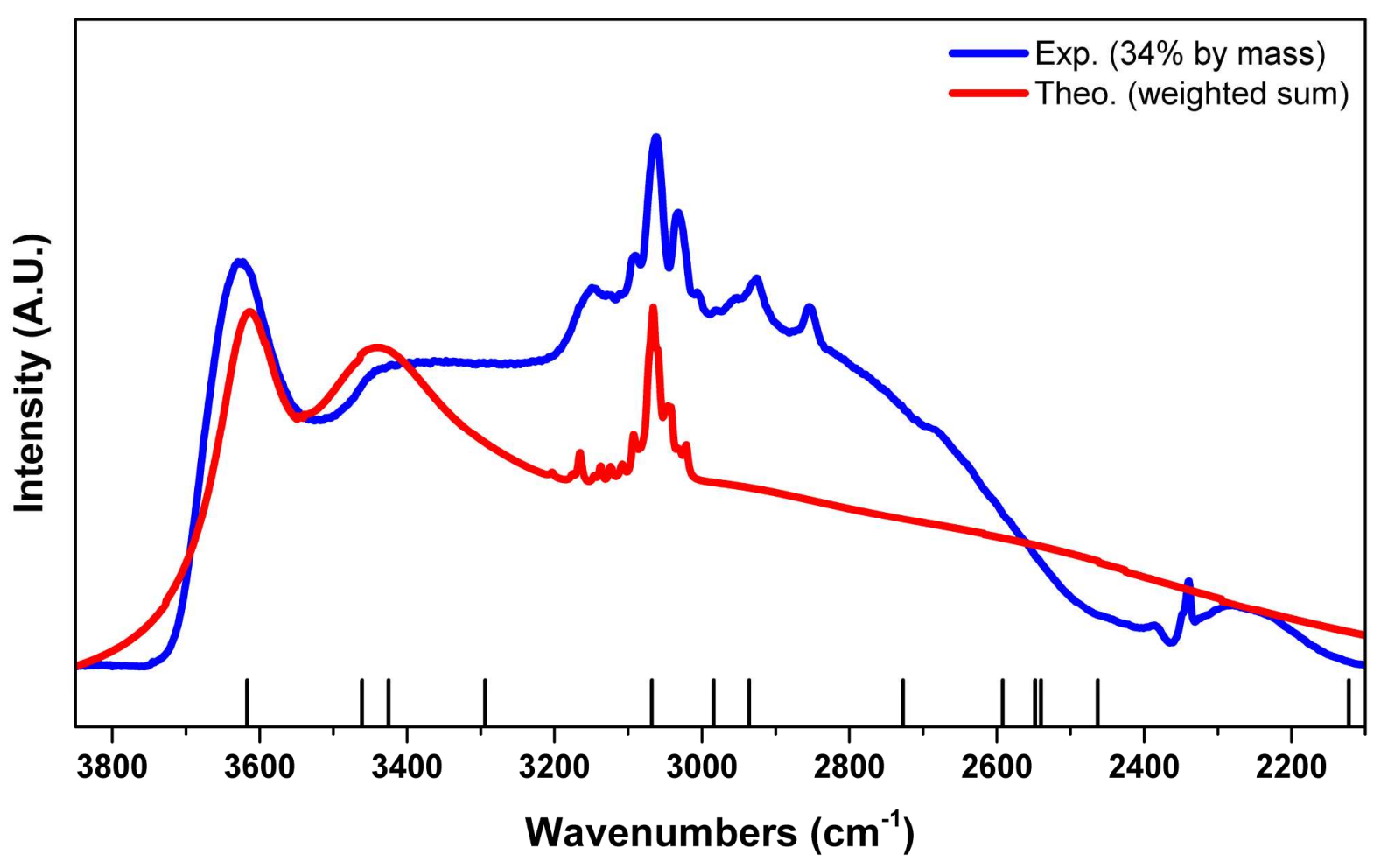

Figure 9. Experimental and simulated IR: experimental FTIR spectrum of MSU-H-CTZ at $34 \%$ by mass, after degas (blue); simulated IR spectrum of CTZ combined with SiOH vibrational contribution (red). At the bottom of the graph, sticks represent the theoretical SiO-H stretching frequencies without Pimentel's correction.

For both the low and high loading cases, the agreement between theory and experiment is remarkable and helps the interpretation of the signals. Considering CTZ modes, the $3175-3100 \mathrm{~cm}^{-1}$ experimental bands are due to the ensemble of the $\mathrm{C}-\mathrm{H}$ symmetric stretching of $\mathrm{SiOH}-\pi$ interacting aromatic rings. Peaks between $3000-2800 \mathrm{~cm}^{-1}$ are due to alkyl impurities in the silica samples. As regards $\mathrm{SiO}-\mathrm{H}$ signals, the sharp peak at $3750 \mathrm{~cm}^{-1}$ (only in the low loading case) corresponds to isolated silanols. The broad band between 3700 and $3550 \mathrm{~cm}^{-1}$ corresponds to the silanol signals of Si$\mathrm{OH}-\pi$ interactions. All silanols signals at lower wavenumbers $\left(3400-2500 \mathrm{~cm}^{-1}\right)$ are due to $\mathrm{SiOH}-$ imidazole interactions. As expected, the SiO-H stretching frequency is highly affected by this interaction, with bathochromic shifts up to more than a thousand wavenumbers, as shown by the individual signals reported in both figures (stick lines) and particularly for the high loading case. The higher intensity of this broad band in both experimental spectra of Figure 8 and 9 with respect to the simu- 
lation is due to the Pimental's approximation which cannot account for all the subtle features due to anharmonic coupling and intensity stealing between modes in H-bond interactions.

A first effect of increasing the drug loading is the loss of the isolated silanol peak, suggesting that all silanols become involved in interactions (see spectra of Figure 8 and 9). A second result is an intensification of the $\mathrm{SiOH}-\mathrm{imidazole}$ signals with respect to the $\mathrm{SiOH}-\pi$ ones, suggesting that a decreasing amount of silanols is able to interact with the phenyl groups and an increasing amount of $\mathrm{SiOH}-$ imidazole H-bonds is formed. Such behavior seems counterintuitive with respect to the energetics of Table 1: computed $\Delta \mathrm{H}^{\mathrm{D}}$ s suggest that by increasing drug loading more stable configurations (imidazole-driven) should be populated earlier than less stable ones (phenyls-driven), while FT-IR shows that $\mathrm{SiOH}-$ phenyls signals are more prominent in the low loading case than the high loading one. This apparent disagreement can be resolved by taking into account the complexity of CTZ adsorption on the silica pore walls. Comparison between computed and experimental enthalpies of adsorption (Table 1) suggests that at least some energetically very stable imidazole-driven interactions (such as that of Figure 3.a) are quite rare in a real sample as they depend on the presence of specific surface sites. Moreover, given the structure of the CTZ molecule, also when it adsorbs through its imidazole ring, more silanols are influenced by its phenyls and chlorophenyls moieties than by the $\mathrm{SiOH}-\mathrm{N}$ interaction. This can be deduced from the individual simulated spectra of Figure 8 , in which signals corresponding to $\mathrm{SiOH}-\pi$ are present in all four configurations, independently on what drives the interaction. Furthermore, the strong bathochromic shift caused by the SiOH-N H-bonds corresponds to a significant signal broadening, so that at low loading these modes are smeared out over the whole spectrum. Finally, AIMD simulations proved that some phenyls-driven adsorptions, although based on relatively weak interactions, are indeed stable at room temperature: given the bulky conformation of CTZ (Figure 1.c) such configurations might be highly probable during incorporation, also at low loadings.

\section{CONCLUSIONS}


We have reported the concurrent experimental and theoretical (both static and dynamic) characterization of a common antifungal drug, clotrimazole (CTZ), incorporated in ordered mesoporous silica of the MSU-H type.

Comparison between experimental and computed interaction energies, pore size distributions and vibrational spectra resulted in a very good agreement. This suggests that DFT simulation of drug adsorption on realistic amorphous silica surface models can be used to predict the behavior of drugs inside the pores of mesoporous silica materials, provided that a good sampling of the different interactions is achieved.

As regards the MSU-H-CTZ system, results shown here reveal that CTZ is adsorbed, over the incorporation with $\mathrm{scCO}_{2}$, following a homogeneous and statistical distribution on the silica surface. This picture is explained only considering together the molecular layer models. Thanks to the quantum mechanical simulations, we were able to describe the experimentally measured change in pore size distribution by considering the thickness of the molecular layer at high loading.

Simulations and their comparison with experimental data suggest that CTZ interacts in multiple orientations with the silica surface: the strongest interaction includes an H-bond between the nitrogen atom of the imidazole ring with terminal silanols of $\mathrm{H}$-bonded chains already present on the silica walls, but other H-bonds that involve the phenyl rings and the chlorine atom are also present. Comparison with experiment shows that a very stable configuration found by the simulations is probably quite rare in the real system due to the specificity of the adsorbing sites.

AIMD simulations provided a direct evidence of high mobility of drugs adsorbed into mesoporous silica, supporting experimental results in literature. We also revealed that large displacements parallel to the surface of adsorbed molecular layers may be triggered by local changes in the interactions. Energetically, it was confirmed that London forces play a key role in drug adsorption on silica and that they are indeed the true driving force of the process in the case of apolar molecules such as CTZ, also assisting the stabilization of molecular layers on the surface. Experimental and theoretical data also agree in that CTZ adsorption on silica and CTZ interaction on its own crystal surfaces are 
almost isoenergetic processes, thus suggesting a possible explanation for the lack of crystallization inside the pores of MSU-H.

A comprehensive picture of this complex scenario was achieved only through the joint of simulation and experiment and the present methodology paves the way to improve our understanding of the interactions between drugs and delivery systems.

\begin{abstract}
ASSOCIATED CONTENT
Supporting Information

Computational details, crystalline structure, surface models, nitrogen adsorption isotherms, AIMD simulations details, FT-IR spectra and bands attribution, absolute energies, fractional coordinates of all the optimized structures and video of the significant AIMD simulations. This material is available free of charge via Internet at http://pubs.acs.org.
\end{abstract}

\begin{abstract}
AKCNOWLEDGMENTS
The vast majority of the calculations have been carried out on the FERMI supercomputer, in Bologna, Italy, thanks to the ISCRA (Italian SuperComputing Resource Allocation) class B projects IBUEXCIP and SIL4SKIN. Models have been visualized and manipulated by MOLDRAW. ${ }^{57}$ AIMD simulations have been analyzed through VMD. ${ }^{58}$ Figures have been rendered with the Tachyon ray tracer, ${ }^{59}$ built into VMD.
\end{abstract}




\section{BIBLIOGRAPHY}

(1) AM Hillery, AW Lloyd, J. S.; Whateley, T. L. Drug Delivery and Targeting: For Pharmacists and Pharmaceutical Scientists; 2002; Vol. 10, pp. 637-637.

(2) Manzano, M.; Aina, V.; Areán, C. O.; Balas, F.; Cauda, V.; Colilla, M.; Delgado, M. R.; Vallet-Regí, M. Studies on MCM-41 Mesoporous Silica for Drug Delivery: Effect of Particle Morphology and Amine Functionalization. Chem. Eng. J. 2008, 137, 30-37.

(3) Song, S.-W.; Hidajat, K.; Kawi, S. Functionalized SBA-15 Materials as Carriers for Controlled Drug Delivery: Influence of Surface Properties on Matrix- Drug Interactions. Langmuir 2005, 21, 9568-9575.

(4) Vallet-Regi, M.; Rámila, A.; Del Real, R. P.; Pérez-Pariente, J. A New Property of MCM-41: Drug Delivery System. Chem. Mater. 2001, 13, 308-311.

(5) Tourné-Péteilh, C.; Lerner, D. A.; Charnay, C.; Nicole, L.; Bégu, S.; Devoisselle, J. M. The Potential of Ordered Mesoporous Silica for the Storage of Drugs: The Example of a Pentapeptide Encapsulated in a MSU-Tween 80. ChemPhysChem 2003, 4, 281-286.

(6) Lai, C.-Y.; Trewyn, B. G.; Jeftinija, D. M.; Jeftinija, K.; Xu, S.; Jeftinija, S.; Lin, V. S.-Y. A Mesoporous Silica Nanosphere-Based Carrier System with Chemically Removable CdS Nanoparticle Caps for Stimuli-Responsive Controlled Release of Neurotransmitters and Drug Molecules. J. Am. Chem. Soc. 2003, 125, 4451-4459.

(7) Vallet-Regí, M. Ordered Mesoporous Materials in the Context of Drug Delivery Systems and Bone Tissue Engineering. Chem.- Eur. J. 2006, 12, 5934-5943.

(8) Andersson, J.; Rosenholm, J.; Areva, S.; Lindén, M. Influences of Material Characteristics on Ibuprofen Drug Loading and Release Profiles from Ordered Micro- and Mesoporous Silica Matrices. Chem. Mater. 2004, 16, 4160-4167.

(9) Mellaerts, R.; Mols, R.; Jammaer, J. A. G.; Aerts, C. A.; Annaert, P.; Van Humbeeck, J.; Van den Mooter, G.; Augustijns, P.; Martens, J. A. Increasing the Oral Bioavailability of the Poorly Water Soluble Drug Itraconazole with Ordered Mesoporous Silica. Eur. J. Pharm. Biopharm. 2008, 69, 223-230.

(10) Izquierdo-Barba, I.; Martinez, A.; Doadrio, A. L.; Pérez-Pariente, J.; Vallet-Regí, M. Release Evaluation of Drugs from Ordered Three-Dimensional Silica Structures. Eur. J. Pharm. Sci. 2005, 26, 365-373.

(11) Herskowitz, A.; Ishii, N.; Schaumburg, H. N-Hexane Neuropathy. A Syndrome Occuring as a Result of Industrial Exposure. N. Engl. J. Med. 1971, 285, 82-85.

(12) Spencer, P. S.; Schaumburg, H. H. Neurotoxic Properties of Certain Aliphatic Hexacarbons. Proc. R. Soc. Med. 1977, 70, 37-39.

(13) Belhadj-Ahmed, F.; Badens, E.; Llewellyn, P.; Denoyel, R.; Charbit, G. Impregnation of Vitamin E Acetate on Silica Mesoporous Phases Using Supercritical Carbon Dioxide. J. Supercrit. Fluids 2009, 51, 278-286. 
(14) Ni, M.; Xu, Q.-Q.; Yin, J.-Z. Preparation of Controlled Release Nanodrug Ibuprofen Supported on Mesoporous Silica Using Supercritical Carbon Dioxide. J. Mater. Res. 2012, 27, 2902-2910.

(15) Gignone, A.; Manna, L.; Ronchetti, S.; Banchero, M.; Onida, B. Incorporation of Clotrimazole in Ordered Mesoporous Silica by Supercritical CO2. Micropor. Mesopor. Mat. 2014, 200, 291-296.

(16) Span, R.; Wagner, W. A New Equation of State for Carbon Dioxide Covering the Fluid Region from the Triple-Point Temperature to $1100 \mathrm{~K}$ at Pressures up to $800 \mathrm{MPa}$. J. Phys. Chem. Ref. Data 1996, 25, 1509-1596.

(17) Pifferi, G.; Restani, P. The Safety of Pharmaceutical Excipients. Farmaco 2003, 58, 541-550.

(18) Azais, T.; Tourne-Peteilh, C.; Aussenac, F.; Baccile, N.; Coelho, C.; Devoisselle, J. M.; Babonneau, F. Solid-State NMR Study of Ibuprofen Confined in MCM-41 Material. Chem. Mater. 2006, 18, 6382-6390.

(19) Guenneau, F.; Panesar, K.; Nossov, A.; Springuel-Huet, M.-A.; Azaïs, T.; Babonneau, F.; Tourné-Péteilh, C.; Devoisselle, J.-M.; Gédéon, A. Probing the Mobility of Ibuprofen Confined in MCM-41 Materials Using MAS-PFG NMR and Hyperpolarised-Xe-129 NMR Spectroscopy. Phys. Chem. Chem. Phys. 2013, 15, 18805-18808.

(20) Mellaerts, R.; Roeffaers, M. B. J.; Houthoofd, K.; Van Speybroeck, M.; De Cremer, G.; Jammaer, J. A. G.; Van den Mooter, G.; Augustijns, P.; Hofkens, J.; Martens, J. A. Molecular Organization of Hydrophobic Molecules and Co-Adsorbed Water in SBA-15 Ordered Mesoporous Silica Material. Phys. Chem. Chem. Phys. 2011, 13, 2706-2713.

(21) Morais, E. C.; Correa, G. G.; Brambilla, R.; Radtke, C.; Baibich, I. M.; dos Santos, J. H. Z. The Interaction of Encapsulated Pharmaceutical Drugs with a Silica Matrix. Colloids Surfaces. B 2013, 103, 422-429.

(22) Rimola, A.; Costa, D.; Sodupe, M.; Lambert, J.-F.; Ugliengo, P. Silica Surface Features and Their Role in the Adsorption of Biomolecules: Computational Modeling and Experiments. Chem. Rev. 2013, 113, 4216-4313.

(23) Delle Piane, M.; Corno, M.; Ugliengo, P. Does Dispersion Dominate over H-Bonds in DrugSurface Interactions? The Case of Silica-Based Materials As Excipients and Drug-Delivery Agents. J. Chem. Theory Comput. 2013, 9, 2404-2415.

(24) Delle Piane, M.; Vaccari, S.; Corno, M.; Ugliengo, P. Silica-Based Materials as Drug Adsorbents: First Principle Investigation on the Role of Water Microsolvation on Ibuprofen Adsorption. J. Phys. Chem. A 2014, 118, 5801-5807.

(25) Delle Piane, M.; Corno, M.; Pedone, A.; Dovesi, R.; Ugliengo, P. Large-Scale B3LYP Simulations of Ibuprofen Adsorbed in MCM-41 Mesoporous Silica as Drug Delivery System. J. Phys. Chem. C 2014, 118, 26737-26749.

(26) Kim, S. S.; Karkamkar, A.; Pinnavaia, T. J.; Kruk, M.; Jaroniec, M. Synthesis and Characterization of Ordered, Very Large Pore MSU-H Silicas Assembled from Water-Soluble Silicates. J. Phys. Chem. B 2001, 105, 7663-7670. 
(27) Hoogerheide, J. G.; Wyka, B. E. Clotrimazole. In Analytical Profiles of Drug Substances; 1982; Vol. 11, pp. 225-255.

(28) Borgers, M. Mechanism of Action of Antifungal Drugs, with Special Reference to the Imidazole Derivatives. Rev. Infect. Dis. 1980, 2, 520-534.

(29) Dovesi, R.; Orlando, R.; Erba, A.; Zicovich-Wilson, C. M.; Civalleri, B.; Casassa, S.; Maschio, L.; Ferrabone, M.; De La Pierre, M.; D’Arco, P.; et al. CRYSTAL14: A Program for the $\mathrm{Ab}$ Initio Investigation of Crystalline Solids. Int. J. Quantum Chem. 2014, 114, 12871317.

(30) Orlando, R.; Delle Piane, M.; Bush, I. J.; Ugliengo, P.; Ferrabone, M.; Dovesi, R. A New Massively Parallel Version of CRYSTAL for Large Systems on High Performance Computing Architectures. J. Comput. Chem. 2012, 33, 2276-2284.

(31) Perdew, J. P.; Burke, K.; Ernzerhof, M. Generalized Gradient Approximation Made Simple. Phys. Rev. Lett. 1996, 77, 3865-3868.

(32) Grimme, S. Semiempirical GGA-Type Density Functional Constructed with a Long-Range Dispersion Correction. J. Comput. Chem. 2006, 27, 1787-1799.

(33) Schafer, A.; Horn, H.; Ahlrichs, R. Fully Optimized Contracted Gaussian-Basis Sets for Atoms Li to Kr. J. Chem. Phys. 1992, 97, 2571-2577.

(34) Nada, R.; Nicholas, J. B.; McCarthy, M. I.; Hess, A. C. Basis Sets for Ab Initio Periodic Hartree-Fock Studies of Zeolite/adsorbate Interactions: He, Ne, and Ar in Silica Sodalite. Int. J. Quantum Chem. 1996, 60, 809-820.

(35) Apra, E.; Causa, M.; Prencipe, M.; Dovesi, R.; Saunders, V. R. On the Structural Properties of NaCl: An Ab Initio Study of the B1-B2 Phase Transition. J. Phys. Condens. Matter 1993, 5, 2969-2976.

(36) Dall'Olio, S.; Dovesi, R.; Resta, R. Spontaneous Polarization as a Berry Phase of the HartreeFock Wave Function: The Case of KNbO3. Phys. Rev. B 1997, 56, 10105-10114.

(37) Hutter, J.; Iannuzzi, M.; Schiffmann, F.; VandeVondele, J. CP2K: Atomistic Simulations of Condensed Matter Systems. Wiley Interdiscip. Rev. Comput. Mol. Sci. 2014, 4, 15-25.

(38) VandeVondele, J.; Krack, M.; Mohamed, F.; Parrinello, M.; Chassaing, T.; Hutter, J. Quickstep: Fast and Accurate Density Functional Calculations Using a Mixed Gaussian and Plane Waves Approach. Comput. Phys. Commun. 2005, 167, 103-128.

(39) Goedecker, S.; Teter, M.; Hutter, J. Separable Dual Space Gaussian Pseudo-Potentials. Phys. Rev. B 1996, 54, 1703-1710.

(40) VandeVondele, J.; Hutter, J. Gaussian Basis Sets for Accurate Calculations on Molecular Systems in Gas and Condensed Phases. J. Chem. Phys. 2007, 127, 114105.

(41) Bussi, G.; Donadio, D.; Parrinello, M. Canonical Sampling through Velocity Rescaling. $J$. Chem. Phys. 2007, 126, 014101. 
(42) Thommes, M.; Köhn, R.; Fröba, M. Sorption and Pore Condensation Behavior of Pure Fluids in Mesoporous MCM-48 Silica, MCM-41 Silica, SBA-15 Silica and Controlled-Pore Glass at Temperatures above and below the Bulk Triple Point. Appl. Surf. Sci. 2002, 196, 239-249.

(43) Verevkin, S. P.; Ralys, R. V.; Zaitsau, D. H.; Emel'yanenko, V. N.; Schick, C. Express Thermo-Gravimetric Method for the Vaporization Enthalpies Appraisal for Very Low Volatile Molecular and Ionic Compounds. Thermochim. Acta 2012, 538, 55-62.

(44) Price, D. M. Vapor Pressure Determination by Thermogravimetry. Thermochim. Acta 2001, $367,253-262$.

(45) Chickos, J. S.; Hosseini, S.; Hesse, D. G.; Liebman, J. F. Heat Capacity Corrections to a Standard State: A Comparison of New and Some Literature Methods for Organic Liquids and Solids. Struct. Chem. 1993, 4, 271-278.

(46) Song, H.; Shin, H.-S. The Antifungal Drug Clotrimazole. Acta Crystallogr. Sect. C Cryst. Struct. Commun. 1998, 54, 1675-1677.

(47) Sliwinska-Bartkowiak, M.; Dudziak, G.; Gras, R.; Sikorski, R.; Radhakrishnan, R.; Gubbins, K. E. Freezing Behavior in Porous Glasses and MCM-41. Colloids Surfaces A Physicochem. Eng. Asp. 2001, 187, 523-529.

(48) Qian, K. K.; Zhou, W.; Xu, X. M.; Udovic, T. J. Characterization of Medicinal Compounds Confined in Porous Media by Neutron Vibrational Spectroscopy and First-Principles Calculations: A Case Study with Ibuprofen. Pharm. Res. 2012, 29, 2432-2444.

(49) Ambrogi, V.; Perioli, L.; Marmottini, F.; Accorsi, O.; Pagano, C.; Ricci, M.; Rossi, C. Role of Mesoporous Silicates on Carbamazepine Dissolution Rate Enhancement. Micropor. Mesopor. Mat. 2008, 113, 445-452.

(50) Ambrogi, V.; Marmottini, F.; Pagano, C. Amorphous Carbamazepine Stabilization by the Mesoporous Silicate SBA-15. Micropor. Mesopor. Mat. 2013, 177, 1-7.

(51) Civalleri, B.; Zicovich-Wilson, C. M.; Valenzano, L.; Ugliengo, P. B3LYP Augmented with an Empirical Dispersion Term (B3LYP-D $\{*\})$ as Applied to Molecular Crystals. CrystEngComm 2008, 10, 405-410.

(52) Ugliengo, P.; Sodupe, M.; Musso, F.; Bush, I. J.; Orlando, R.; Dovesi, R. Realistic Models of Hydroxylated Amorphous Silica Surfaces and MCM-41 Mesoporous Material Simulated by Large-Scale Periodic B3LYP Calculations. Adv. Mater. 2008, 20, 4579-4583.

(53) Zhuravlev, L. T. Concentration of Hydroxyl Groups on the Surface of Amorphous Silicas. Langmuir 1987, 3, 316-318.

(54) Tsuzuki, S.; Honda, K.; Uchimaru, T.; Mikami, M.; Tanabe, K. Origin of Attraction and Directionality of the $\Pi / \pi$ Interaction: Model Chemistry Calculations of Benzene Dimer Interaction. J. Am. Chem. Soc. 2002, 124, 104-112.

(55) Connolly, M. L. Computation of Molecular Volume. J. Am. Chem. Soc. 1985, 107, 11181124. 
(56) Pimentel, G. C.; Sederholm, C. H. Correlation of Infrared Stretching Frequencies and Hydrogen Bond Distances in Crystals. J. Chem. Phys. 1956, 24, 639-641.

(57) Ugliengo, P.; Viterbo, D.; Chiari, G. MOLDRAW: Molecular Graphics on a Personal Computer. Zeitschrift für Krist. 1993, 208, 383-383.

(58) Humphrey, W.; Dalke, A.; Schulten, K. VMD: Visual Molecular Dynamics. J. Mol. Graph. 1996, 14, 33-38.

(59) Stone, J. An Efficient Library for Parallel Ray Tracing and Animation. In Intel Supercomputer Users Group Proceedings; Computer Science Department, University of Missouri-Rolla, 1995; pp. 1-5. 


\section{GRAPHICS TABLE OF CONTENTS}

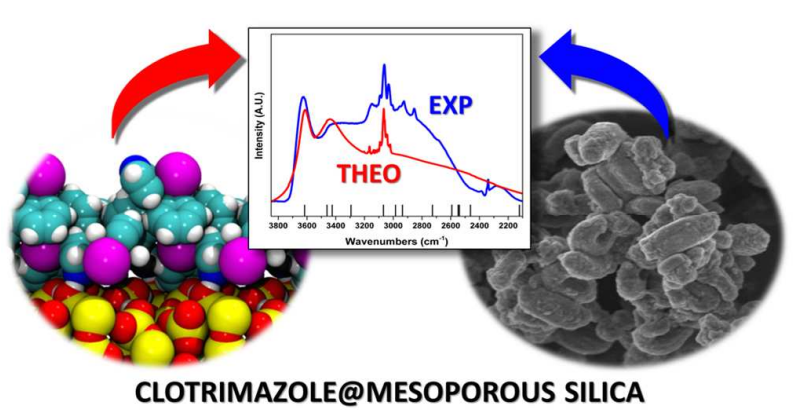

19

20

21

22

23

24

25

26

27

28

29

30

31

32

33

34

35

36

37

38

39

40

41

42

43

44

45

46

47

48

49

50

51

52

53

54

55

56

57

58

59

60 
a)<smiles>Clc1ccccc1C(c1ccccc1)(c1ccccc1)n1ccnc1</smiles>

c)

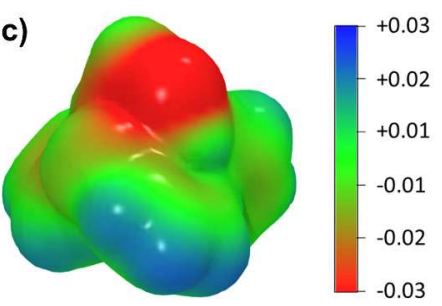

b)
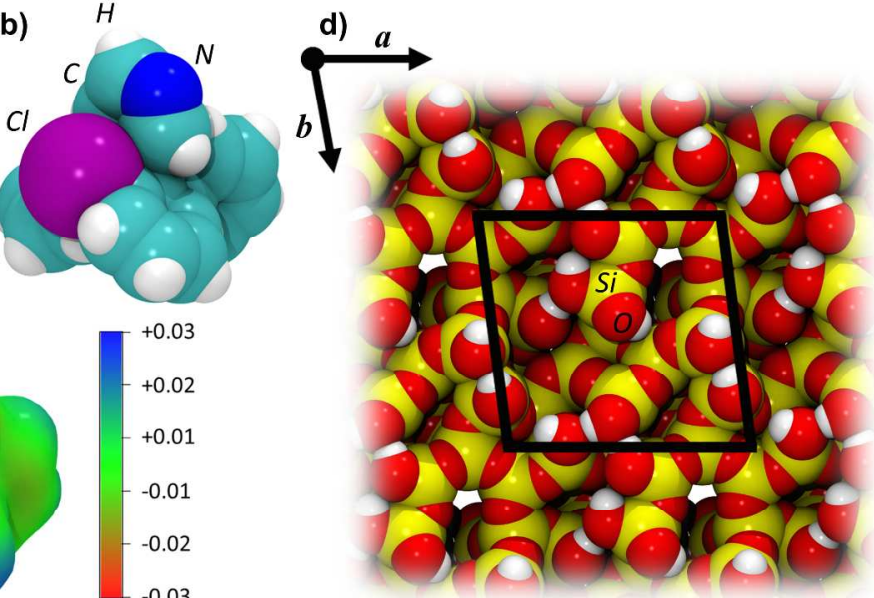

$267 \times 140 \mathrm{~mm}(300 \times 300$ DPI) 
a) imidazole (I)

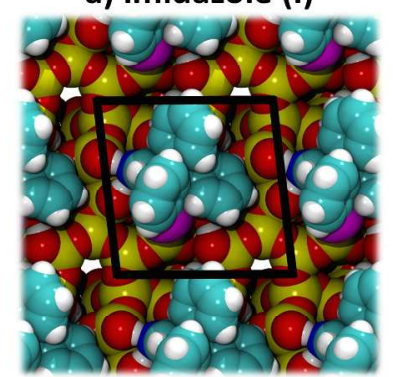

c) phenyls (I)

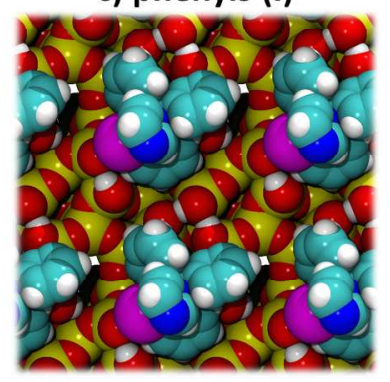

b) imidazole (II)

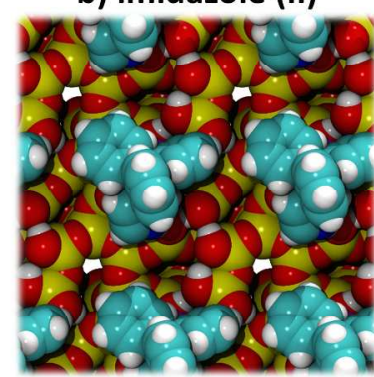

d) phenyls (II)

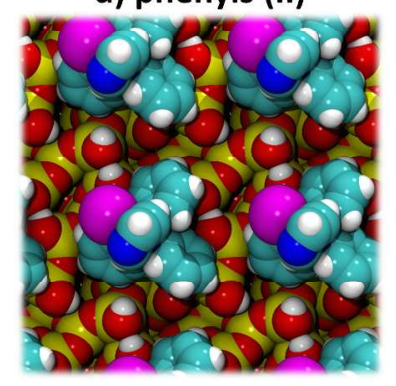

$245 \times 165 \mathrm{~mm}(300 \times 300 \mathrm{DPI})$ e) molecular layer (I)

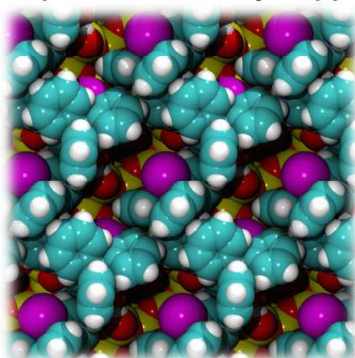

f) molecular layer (II)

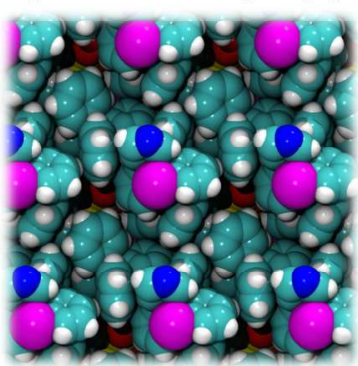




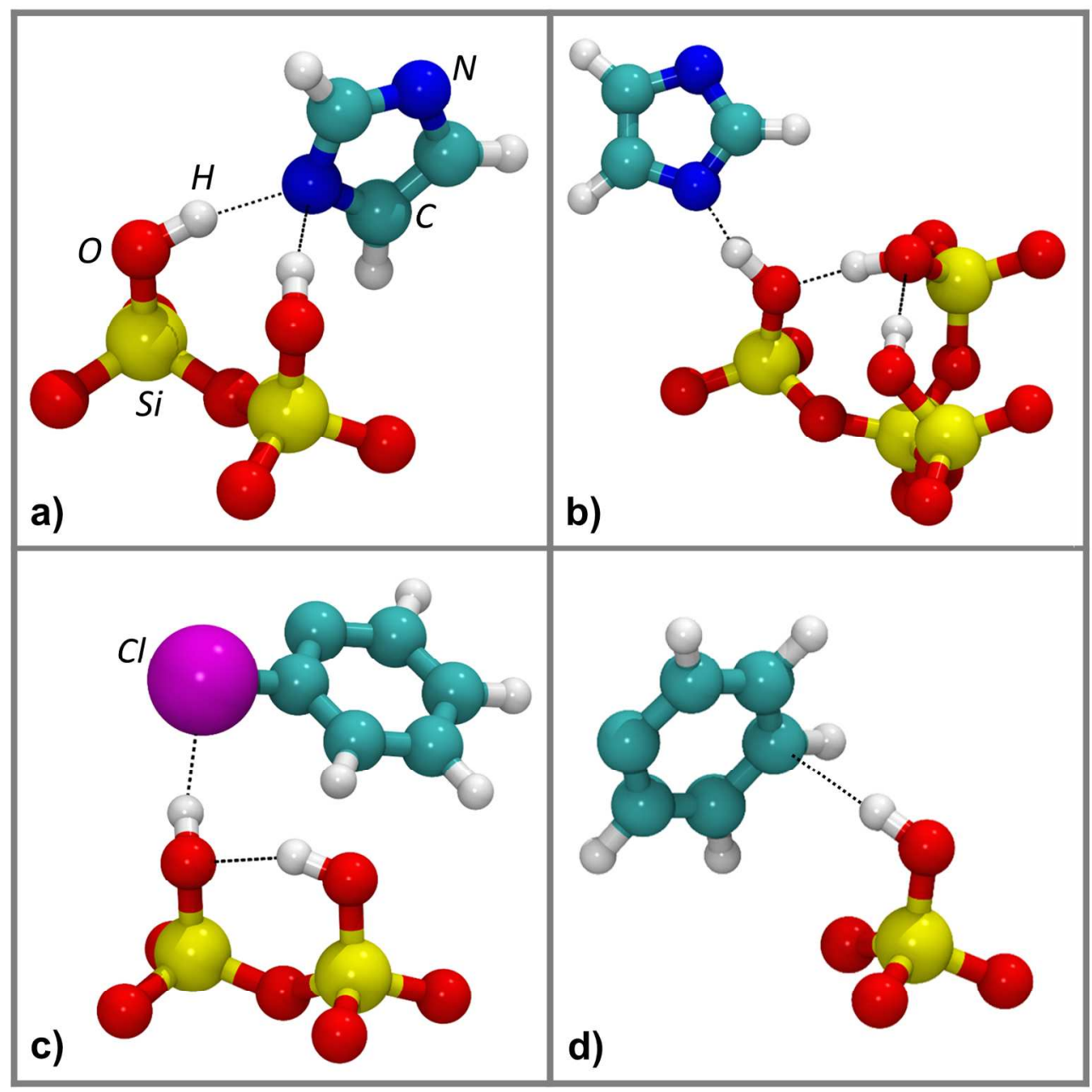

$180 \times 180 \mathrm{~mm}(300 \times 300 \mathrm{DPI})$ 
b)

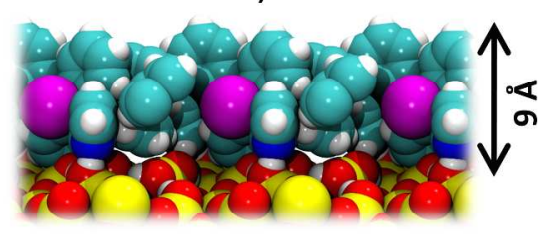

c)

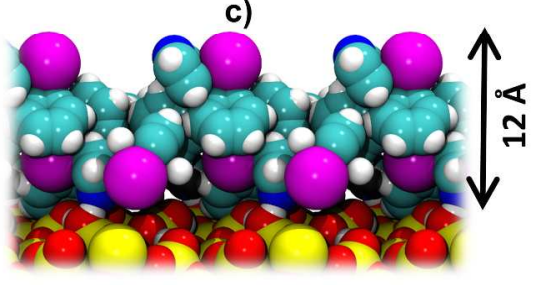

$256 \times 129 \mathrm{~mm}(300 \times 300 \mathrm{DPI})$ 

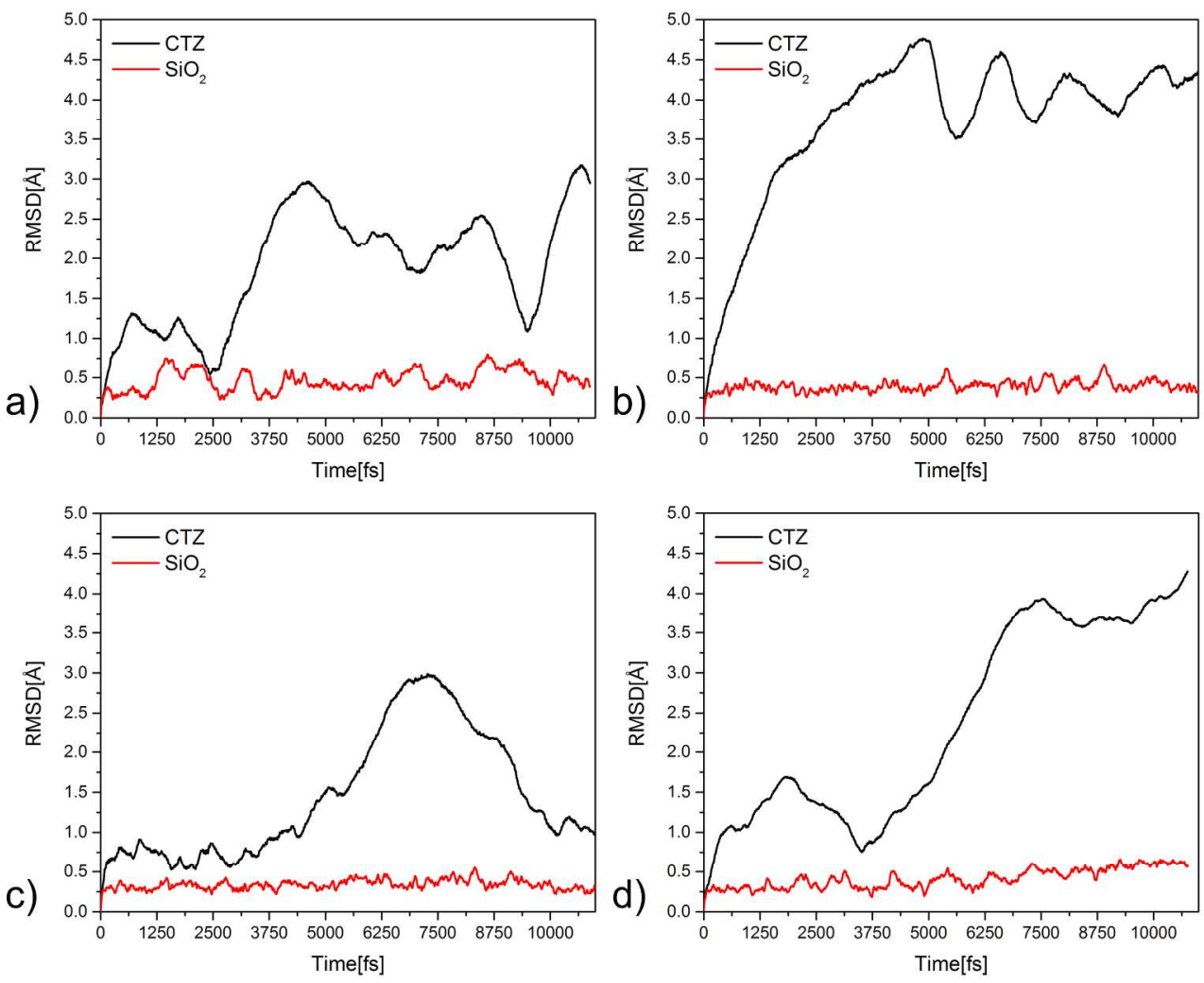

$221 \times 178 \mathrm{~mm}(300 \times 300$ DPI $)$ 
a)

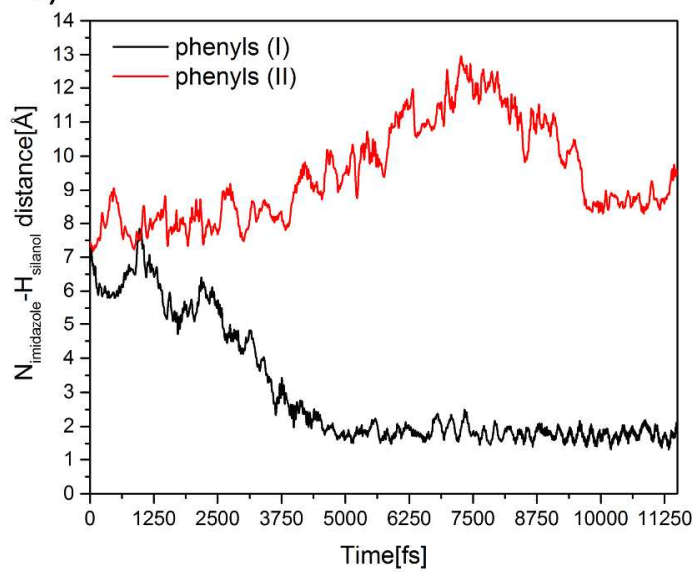

b)

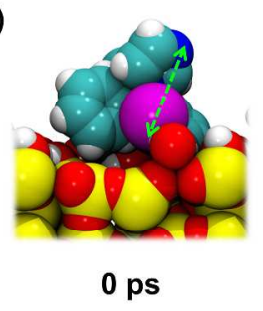

c)

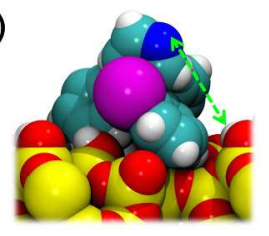

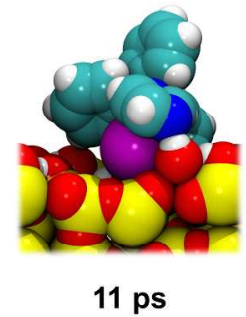

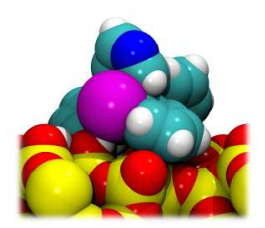

$305 \times 149 \mathrm{~mm}(300 \times 300$ DPI $)$ 

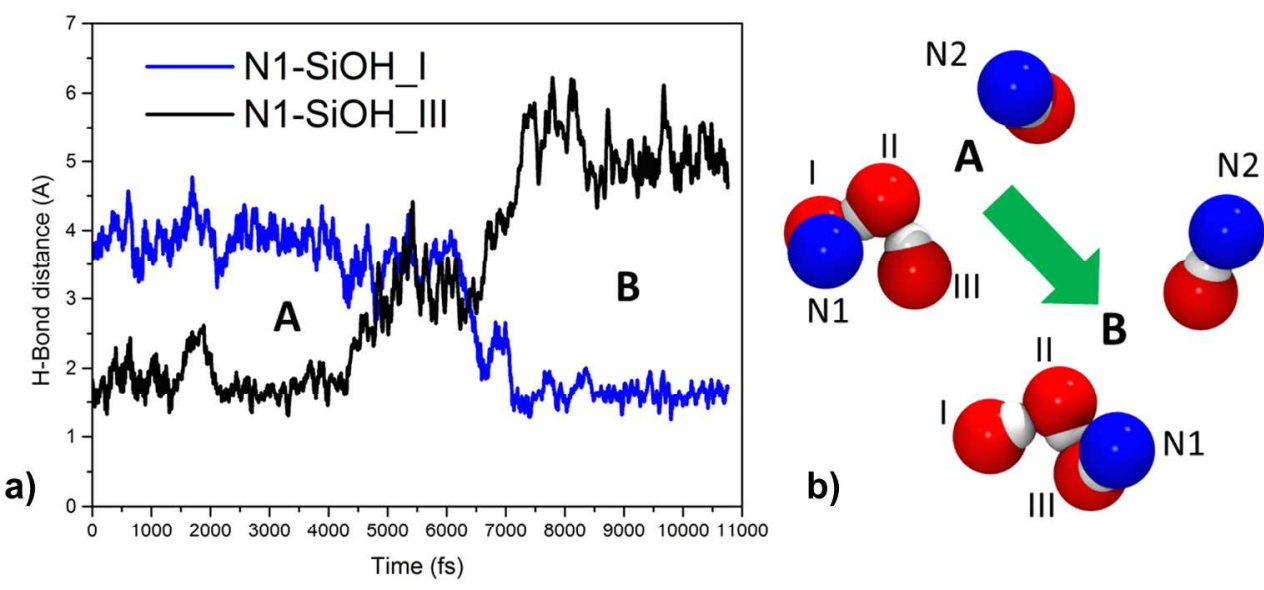

c)

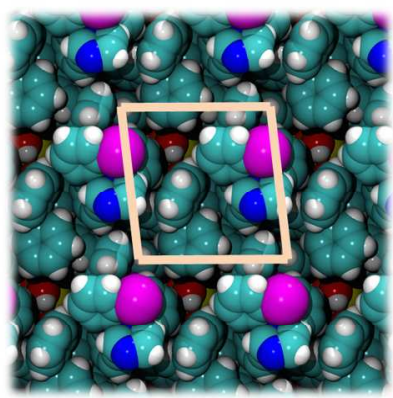

0 ps $(\Delta E=-117)$

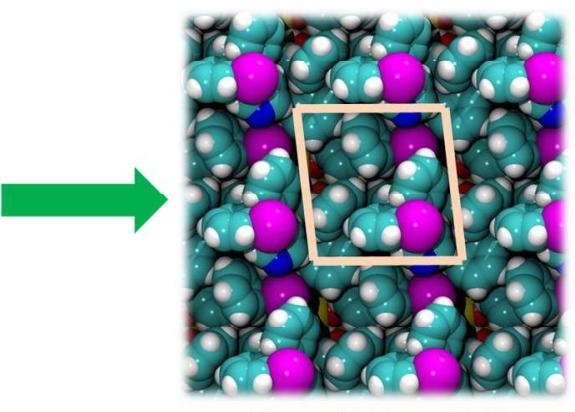

11 ps $(\Delta E=-130)$

$225 \times 183 \mathrm{~mm}(300 \times 300$ DPI $)$ 


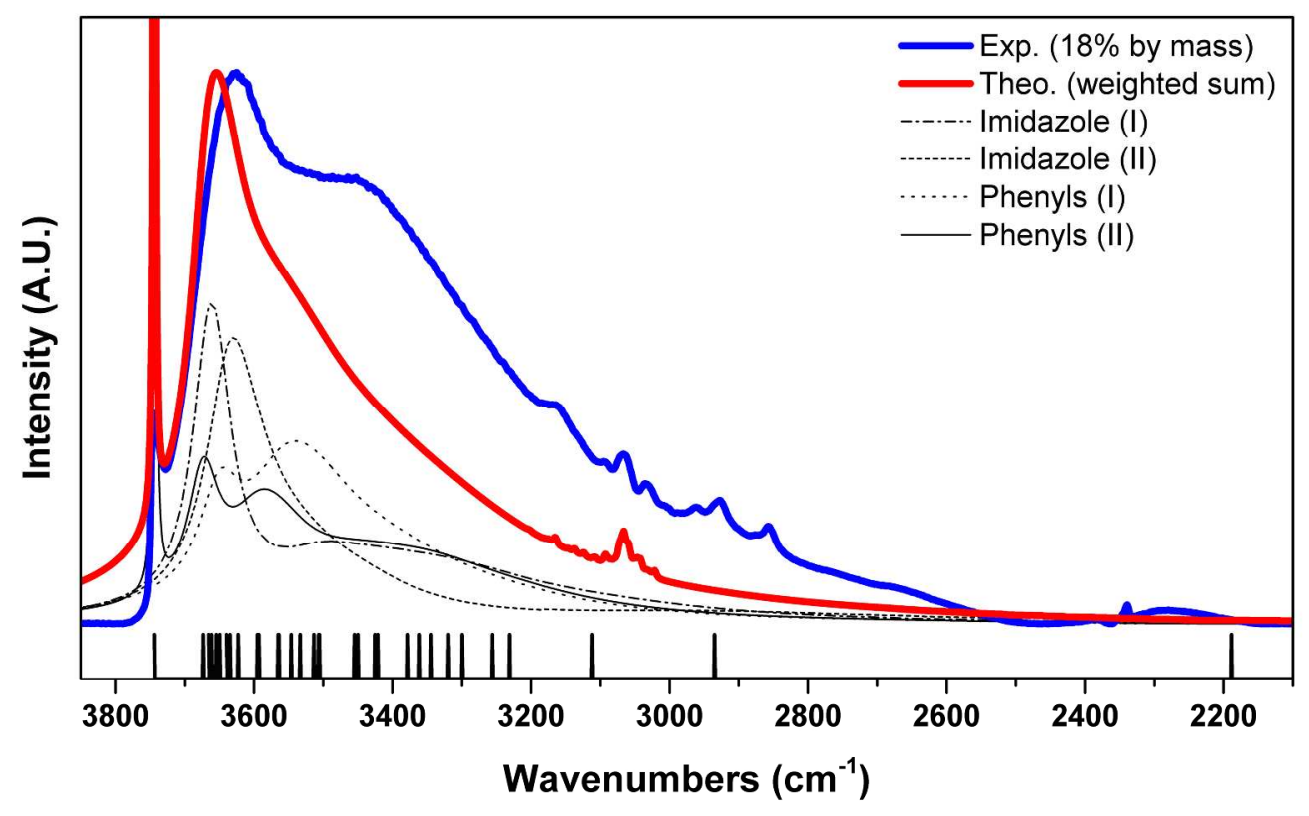

$268 \times 168 \mathrm{~mm}(300 \times 300 \mathrm{DPI})$ 


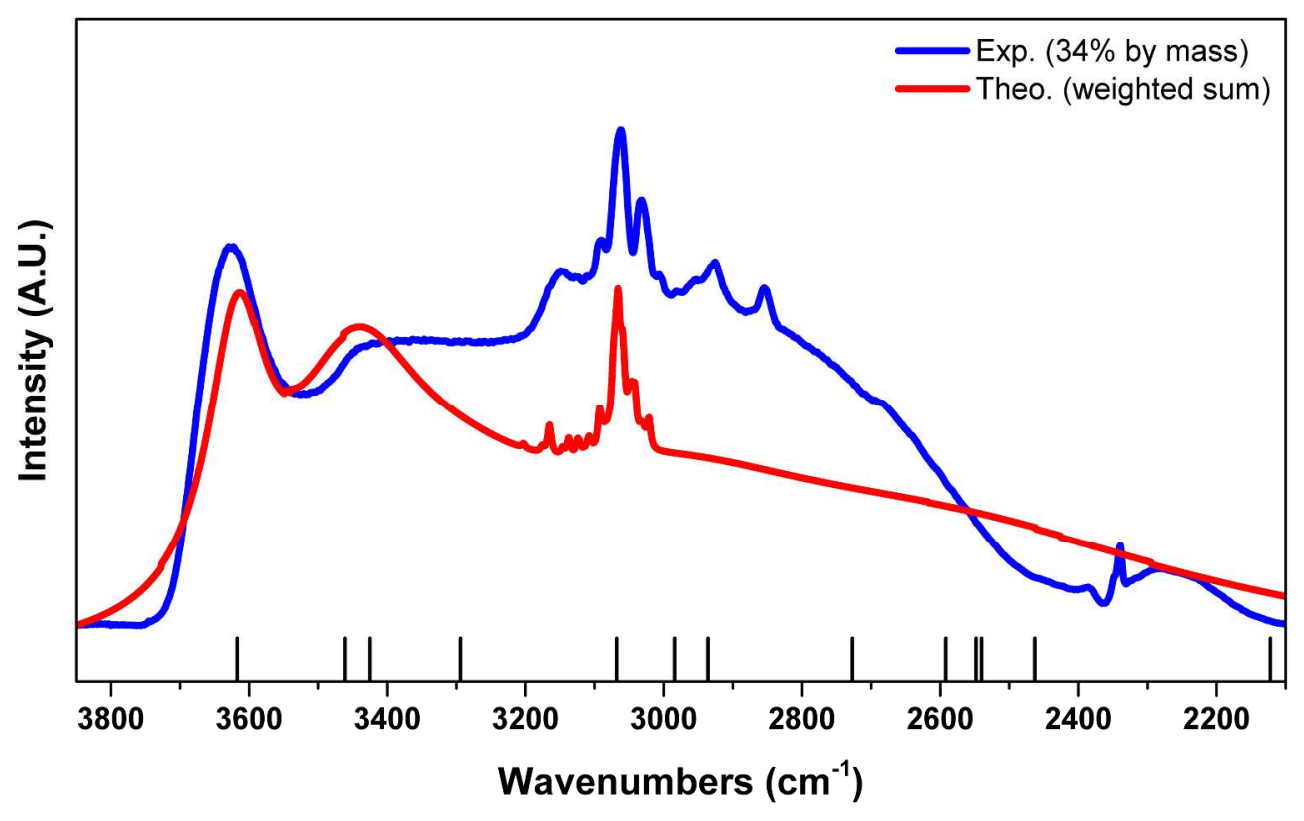

$270 \times 169 \mathrm{~mm}(300 \times 300$ DPI $)$ 